Portland State University

PDXScholar

$1-1-1982$

\title{
A study of the personality characteristics of tinnitus patients
}

Gloria E. Reich

Portland State University

Follow this and additional works at: https://pdxscholar.library.pdx.edu/open_access_etds Let us know how access to this document benefits you.

Recommended Citation

Reich, Gloria E., "A study of the personality characteristics of tinnitus patients" (1982). Dissertations and Theses. Paper 7.

https://doi.org/10.15760/etd.7

This Thesis is brought to you for free and open access. It has been accepted for inclusion in Dissertations and Theses by an authorized administrator of PDXScholar. Please contact us if we can make this document more accessible: pdxscholar@pdx.edu. 


\title{
A STUDY OF THE \\ PERSONALITY CHARACTERISTICS \\ OF TINNITUS PATIENTS
}

\author{
by \\ GLORIA E. REICH \\ A thesis submitted \\ in partial fulfillment of the \\ requirements for the degree of
}

MASTER OF SCIENCE

in

PSYCHOLOGY

Portland State University 1982 
TO THE OFFICE OF GRADUATE STUDIES AND RESEARCH:

The members of the Committee approve the thesis of Gloria E. Reich presented July 20, 1982.

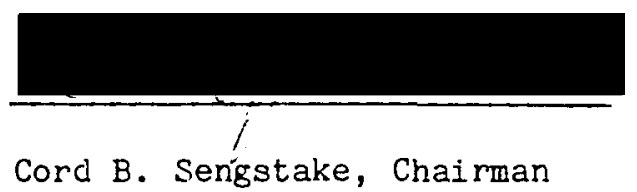

Cord B. Sengstake, Chairman

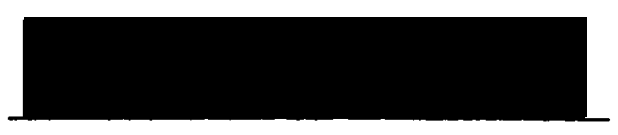

Robert M. Johnson

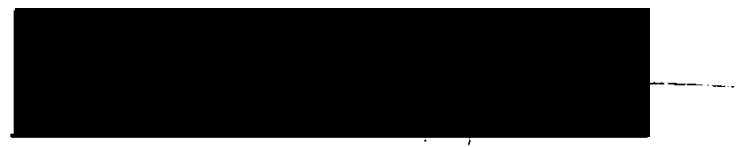

Chadwick Karr

APPROVED:

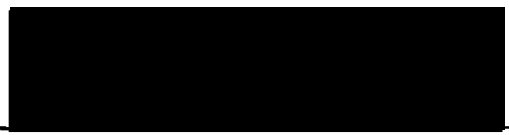

David Hrench, Head, Department of Psychology

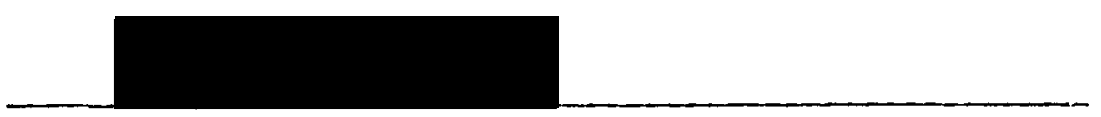

Stanley E. Rauch, Dean of Graduate Studies and Research 
AN ABSTRACT OF THE THESIS OF Gloria E. Reich for the Master of Sciences in Psychology presented July 20, 1982.

Title: A Study of the Personality Characteristics

of Tinnitus Patients

APPROVED BY MEMEERS OF THE THESIS COMMITTEE:
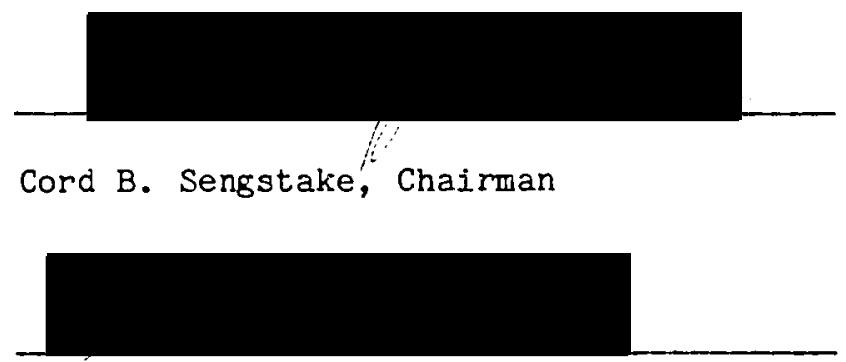

Robert M. Johnson

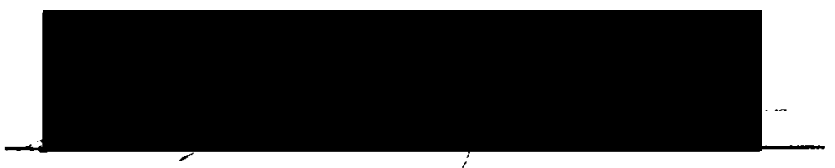

Chadwick Karr

A short form of the Minnesota Multiphasic Personality Inventory was administered to 146 clinical patients who suffered from either tinnitus or a hearing disorder or both. 
Patients wcre aisigned to four groups on the basis of their subjective complaint and their audiometric report: patients with tinnitus only, patients with tinnitus and a hearing loss where the tinnitus was the primary complaint, patients with tinnitus and a hearing loss where the hearing loss was the primary complaint, and patients who had a hearing loss but no tinnitus. The purpose of the study was to determine whether there were certain measurable personality characteristics unique to the tinnitus patient. The results indicated elevations for all four groups on some combination of Scales $8,6,3$, and 2 . The differences obtained were significant between those groups who suffered from tinnitus as opposed to those whose primary complaint was a hearing loss. The tinnitus patients had social adjustment problems that were not evidenced for patients with hearing impairment. This finding was especially true for patients whose only problem was tinnitus. It appears that for those patients with both a hearing loss and tinnitus the scores are less elevated, indicating that the patient who has had a hearing loss for a period of time is better able to cope with the tinnitus than the patient who is suddenly and unaccountably afflicted with tinnitus. Thus, it is reasonable to conclude that the MMPI can be used as an instrument to differentiate between the tinnitus versus the hearing loss patient. 


\section{ACKNOWLEDGMENTS}

It is with sincere appreciation that the author acknowledges the help and guidance of the Psychology Department members of the thesis committee, Dr. Cord B. Sengstake and Dr. Chadwick Karr, in the preparation of this study.

Very special thanks are due to my friend, Dr. Robert M. Johnson, for his generous contribution of time and talent during the course of this investigation.

The author is particularly grateful to Dr. Jack Vernon and the entire staff of the Kresge Hearing Research Laboratory for their encouragement and help. Without their inspiration, instruction, friendship, and patience, this study could not have been undertaken.

Sincere gratitude is due my husband, Ted, and our children, Evy and David, who have all contributed with tolerance and understanding to the successful completion of this project. 
TABLE OF CONTENTS

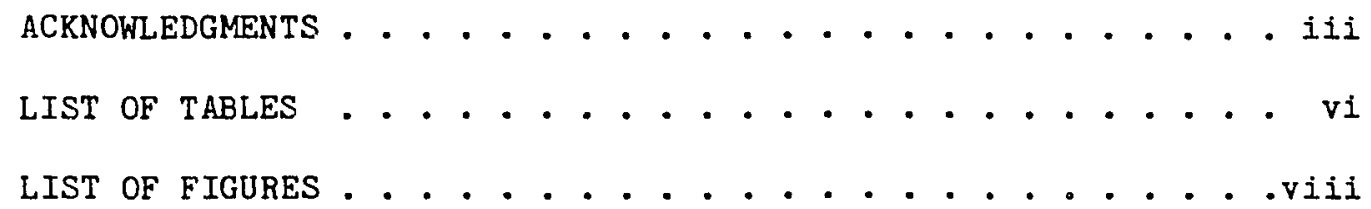

CHAPTER

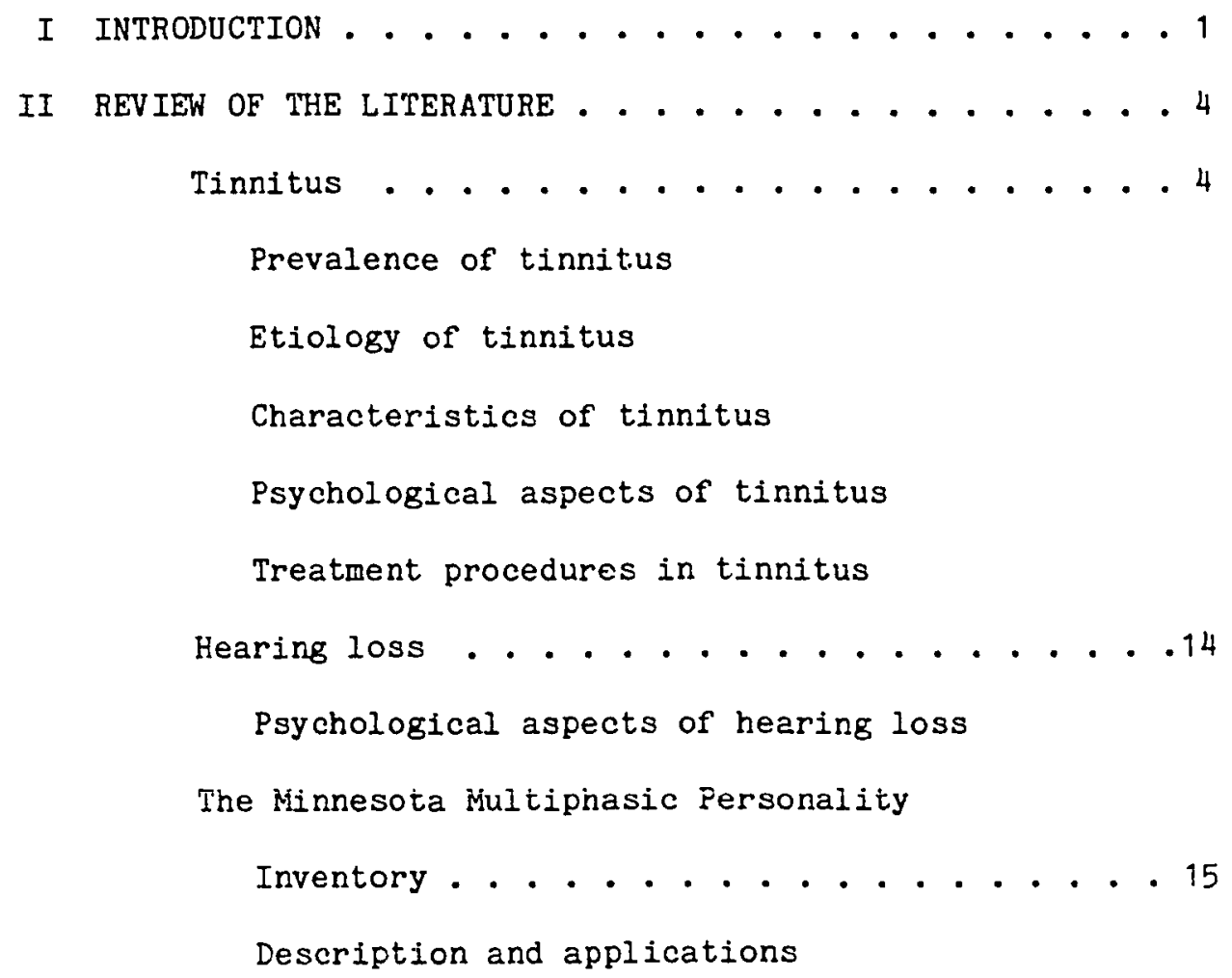


III METHOD. • • • • . . • . • • • • . . . . . . 22

Subjects

Test instrument

Test procedure

Statistical analysis

IV RESULTS AND DISCUSSION . . . . . . . . . . . . 30

Group I: Patients with tinnitus and

normal hearing sensitivity

Group II: Patients whose primary

complaint is tinnitus but who

also have a hearing loss

Group III: Patients who are chiefly

troubled by hearing loss but who

also have tinnitus

Group IV: Patients who suffer from

hearing loss but do not have

tinnitus

The combined groups, all the patients

in the study

V SUMMARY AND CONCLUSIONS . . . . . . . . . . . . 65

BIBLIOGRAPHY . . . . . . . . . . . . . . . . . 70

APPENDIX . . . . . . . . . . . . . . . . 76 


\section{LIST OF TABLES}

TABLE

PAGE

I MMPI I Score Means and Standard

Deviations for Group I, Patients

with Tinnitus and Normal Hearing. . . . . 34

II MMPI I Score Means and Standard

Deviations for Group II, Patients

who have Hearing Loss and Tinnitus,

Tinnitus being the Primary Complaint. . . . 38

III MMPI I Score Means and Standard

Deviations for Group III, Tinnitus

Patients whose Primary Complaint is

their Hearing Loss . . . . . . . . . 42

IV MMPI I Score Means and Standard

Deviations for Group IV, Patients

with Hearing Loss but not Tinnitus... . . . 45

V Comparison of the Groups with Hearing

loss, Groups II, III and IV, with

Data Presented on Hard-of-Hearing

Individuals by Myklebust (1960) . . . . . . 47

VI The Percent of $I$ scores above 70 on

One or More Scales of the MMPI . . . . . . 49 
VII Univariate $\mathrm{E}$ ratios

Variables Reaching Significance $(p<.05)$. . . . 50

VIII Student's t Probabilities for the

Differences Between Means of the Four

Groups and Combinations of the Groups

for Each of the 13 MMPI Scales ....... . 51

IX Percent of Patients in Each Group who

had Elevated Scores on the MMPI Scales . . . . 53

X t Statistic Between 50,000 Me:'ical

Patients and 146 Patients in this Study. . . . . 55

XI A Comparison of Age Range of Patients in

this Study with the Medical Population

in the MMPI Source Book (Swenson et

al., 1973). . . . . . . . . . . 56

XII Summary of SPSS Discriminant

Analysis results ............ . 60

XIII The Number and Percent of Patients

Having Two or More I Scores

above 70 on the MMPI .............. 61 
LIST OF FIGURES

FIGURE

PAGE

1. Age Means and Mean Values of MMPI

I Scores for All Groups . . . . . . . . 32

2. Mean Values of MMPI I Scores for Group I . . . . . 35

3. Mean Values of MMPI $I$ Scores for Group II . . . . 39

4. Mean Values of MMPI I Scores for Group III . . . . 43

5. Mean Values of MMPI I Scores for Group IV . . . . 46

6. Mean Values of MMPI T Scores

for Hard-of Hearing Patients

(Myklebust, 1960) ........... 48

7. Mean Values of MMPI I Scores for Medical

Population of the University of

Minnesota (Swenson et al., 1973) . . . . . 57

8. Mean Values of MMPI $\underline{T}$ Scores for Patients

with Aphasia or Epilepsy or Tinnitus . . . . . 58 


\section{CHAPTER I}

INTRODUCTION

Tinnitus is the perception of sound, i.e., ringing in the ears or head noises, when no external stimulus is present. The National Center for Health Statistics (1968) estimates that as many as 20 percent of the population are troubled by tinnitus at some time during their lives. About 4 percent of the population is severely troubled by the problem. While tinnitus occurs in patients of all ages, it most commonly occurs among adults, especially those who have hearing problems. Many patients who are troubled by tinnitus either report or have been observed to have difficulties which appear to be primarily psychological in nature. Tinnitus is suspected to have a deleterious effect on personality (Myklebust, 1960). It is quite common for patients to say that they find their tinnitus stressful. Stress in this instance would be either that stimulus which provokes bodily reactions or the state of bodily reaction resulting from factors (the tinnitus)that alter an existing equilibrium. If the individual is able to adapt and deal effectively with the stress, then the anxiety accompanying that stress may subside. But if the adaptive mechanisms fail and the tinnitus continues to affect behavior, then one's perceptual interpretation of the environment might be modulated and elements associated with the stress such as tinnitus may be concentrated forming a rather narrow perspective of that social 
with stress are grave. Failure to cope can cause psychological reactions including depression, withdrawal, physical illness and even sulcide. It is essential, therefore, to determine ways by which the affected individual can better adapt to his or her situation. Can the condition that is producing the stress be modified? In the case of tinnitus, modification can sometimes be achieved through treatment. It is not possible to say whether tinnitus is a causal factor in personality disorders or whether those with personality disorders are more likely to have tinnitus. If the tinnitus patient experiences a greater number of personality defects tiran the normal population, it might be possible to find some answers by identifying personality characteristics that are typical of tinnitus patients. Follow-up studies using similar measures could then be conducted to try to determine whether successful treatment of the condition alters personality. The purpose of this study, therefore, is to determine whether there are certain measurable personality characteristics unique to the tinnitus patient. The hypothesis states that tinnitus patients, or patients with both tinnitus and hearing loss, where the tinnitus is perceived as the greater problem, would have personality characteristics that differentiate them from patients with hearing loss alone, or with both hearing loss and tinnitus where the hearing loss is perceived to be the greater problem. In order to test this hypothesis, a personality inventory, the MMPI 168 (Overall \& Hunter, 1973), was used to test four groups of patients, one with tinnitus and no hearing loss, one with hearing loss and no tinnitus, and two groups with both tinnitus and 
hearing loss, one perceiving tinnitus as the greater problem and the other perceiving the hearing loss as the greater problem. The findings for these four groups were analyzed in terms of the personality characteristics of each group.

A number of statistical procedures were employed that allowed examination of the data in hopes of answering the following research questions:

1) Are there signigicant differences between the scores on the various scales of the MMPI for Groups I and II versus Groups III and IV? 2) Are there significant differences between the scores on the different scales of the MMPI for Groups II and III?

3) Is it possible to select scales that will differentiate between these four groups?

4) Are there general statements that can be made about the tinnitus clinic population? 
CHAPTER II

REVIEW OF THE LITERATURE

TINNITUS

\section{Brevalence of tinnitus}

Tinnitus occurs in all age groups and apptars to be a worldwide problem. Several decades ago, Fowler(1955) wrote that 85 percent of an otolaryngologist's patients could be expected to have tinnitus. Tinnitus is a symptom that is of ten associated with other hearing problems. However, some patients with normal hearing also refort having tinnitus. This may account for the greater reported incidence of tinnitus than of hearing impairment. The NINCDS Factbook (1981) reported 13,400,000 estimated cases of deafness or partial deafness in the United States, whereas The National Institutes of Health survey done in the 1960's identified 37 million adults as having tinnitus. More recent studies are in progress and it is expected that an even greater incidence of tinnitus will be reported when these studies are published. It is generally accepted that hearing disorders are the most prevalent handicap in our society, and few people escape having hearing problems sometime during their lives. The NIH survey was concerned with adult responses only, but when the figures were extrapolated to cover all age groups, an inciderce of tinnitus equal to about 18 percent of 
the population was found. The first compilation of patient data at the Oregon Health Sciences Center Tinnitus Clinic showed an average patient age of around 65 years. When another compllation was made two or three years later, the average age had dropped to around 51 years (Vernon, 1982). Cirildren seldom mention tinnitus or hearing loss unless these are associated with some painful experience. However, a study made recently in the London school system indicates that children who have a hearing impairment also have a high incidence of tinnitus (Graham, 1981). Furthemore, young adults are reporting tinnitus and hearing impairment in increasing numbers. The character of rodern society in which one's ears are bombarded with sound in the environment, in the workplace, and during recreational activities will surely provoke hearing disorders and tinnitus in a higher proportion of the general population (Vernon, 1977 .

\section{Etiology of tinnitus}

Tinnitus is known to be caused by many factors. Virtualiy anything that can damage hearing can cause tinnitus. A specific event, such as an explosion or unusually loud noise, or a combination of events such as a long history of working in a noisy environment, can cause tinnitus. Certain physical conditions appear to be associated with tinnitus, such as high blood pressure, some food allergies, dental anomalies such as temporomandibular joint dysfunctions (Reiter, 1980), as well as the more serious problems of acoustic neuromas and vascular pathologies of the auditory area (Goodhill, 1950). Specifically, however, the etiology of 
tinnitus remains elusive.

\section{Characteristics of tinnitus}

Patients describe their tinnitus in many ways. Some of the more common adjectives used to describe tinnitus are ringing, hissing, buzzing, roaring, whistling, and cricket-like. Often the measurements that can be made objectively do not reflect adequately the way the person perceives the tinnitus. Measurements of the amount of sound needed to cover a person's internal sound are frenuently less than one would suspect, having heard the patient refer to his tinnitus as being nunbearably loud." (Goodwin \& Johnson, 1980)

In planning testing and treatment procedures, the clinician sometimes utilizes the way the patient describes the sound. The severity of the patient's tinnitus can be thought of as a continum ranging from the mildest form of tinnitus, which is noticed only occasionally by the patient and easily ignored, to tir severest form where the patient is constantly bothered and can attend with great difficulty to little else.

\section{Bsychelegical aspects of tinnitus}

Often a feeling of hopelessness arises when the individual is told that there is nothing that can be done to relieve tinnitus. Whether or not this is true for that individual may or may not have been witermined, but the seeds of helpless behavior have been planted with that simpie statement. The person who passively accepts a verdict like this can lose hope for future success. That person might also feel 
inadequate to deal with the problem and could even inagine that it prevents him or her from attaining whatever life goals have been envisioned. These problems in living that confront the tinnitus patient are sometimes reported by the patient and sometimes observed by clinicians who are called os for help. Less frequently are these problems severe enough that the patient will have sought psychiatric counseling (House, 1981).

Certain psycholorisal problems have been observed in reition to hearing loss, and many patients who are troubled by tinnitus also report having psychological difficulties (Vernon, 1982). Often patients who have tinnitus and hearing loss worry that the difficulty in hearing is related to the tinnitus. Sometimes correcting the hearing loss is enough to make that person able to cope with the tinnitus. However, there are also patients who have normal hearing and who suffer greatly from tinnitus and its associated stress. One of the most common psychopathologies clinically observed in tinnitus patients is depression (Johnson, 1982). Feelings of hopelessness, self-pity, inadequacy, along with a dependence on others to solve problems, withdrawal from social situations, and frequency of other 11 lnesses are examples of these depression-related states. "Tinnitus is a stress" (Ambrosino, 1981, p.169). Some tinnitus patients have been so distressed that they have committed suicide to escape the noise. Selye(1974) characterizes stress as the nonspecific response of the body to any demand made upon it. When the body is chronically in this state of readiness to respond, its adaptability is diminished and the person involved is less flexible to 
cope with the everyday problems of living. When the stressful situation, either caused by the tinnitus or contributing to the tinnitus, becomes unbearable, the patient is likely to exhibit behaviors that are disorganized or pathological.

The psychological state of the patient at the time tinnitus is first perceived seems to be an important factor in the manner in which the patient relates to the problem. Tinnitus can be little more than a nuisance to a person who is well integrated but can be a major source of suffering to someone already having problems with living. When a patient becomes overly concerned about tinnitus, a vicious circle can be initiated where the anxiety exacerbates the tinnitus; the patient becomes more anxious an: 'he tinnitus seems to worsen (Vernon, 1982).

Frankenhaeuser \& PLChi. (1964) have shown that when people perform tasks requiring sustained concentration under distracting conditions, their continuation of these tasks will result in a depletion of the Energy reserves and cause fatigue even though hormones to sustain these reserves are still being secreted at the same level. It is possible that the sustained annoyance of the stress of tinnitus may account for the inability to endure long periods of concentration and fatigue that is reported by many tinnitus patients.

Patients arriving at the oregon Health Sciences Center Tinnitus Clinic have of ten sought other forms of treatment for tinnitus. If these have included psychiatric counseling, the patient might complain that the psychiatrist was not accepting the fact that something was organically wrong. Weinshel(1955) presents the psychoanalytical view of 
tinnitus, characterizing it in the Freudian manner with emphasis on early childhood problems. He points out the importance of the formation of the superego and the role in its development through the spoken words and commands of the purent. The 'voice' of conscience can be utilized to explain some of the guilt feelings that many patients associate with tinnitus. In some patients, the ear noise is regarded as something harmful and threatening. In others, the ear noise has become a persecutor and elicits paranoid reelings. However, most individuals who experience tinnitus do not appear to suffer from psychological effects attributable to tinnitus. In fact, most seem able to cope with the problem. Problems like tinnitus can exacerbate character anomalies and, if the situation worsens, the tinnitus may serve as a focus for phobic fears, obsessive ruminations, depression, and a variety of hostile or guilt feelings. In summary, it has been noted that tinnitus is stressful and gives rise to feelings of anxiety. The body reacts as though it were being constantly threatened. If this situation exceeds a person's capacity for coping, then a pathological state can result. Response to stress is highly individual. Tolerable stress for one person may be intolerable distress, discomfort, and incapacity for another.

\section{Treatment procedures in tinnitus}

Historically, treatments for tinnitus have been reiatively ineffective. Patients who had tinnitus and sought medical treatment were usually told that they must learn to live with it or were given drugs to ease anxiety. Fowler (1955, p. 33) stated that ${ }^{\text {if }}$ a patient 
is shown that the deafness or head noises should not really be unbearable, that they are not going to result in insanity or total deafness,..." then he can be helped to tolerate his symptoms. Fowler also said that ntinnitus...may be temporarily smothered by many narcotics, seratives, and a few drugs, notably procaine; but relie:" will be transitory unless the emotional factors are also relieved or removed."

Coping strategies differ from patient to patient, but in the absence of effective treatment for most patients, such strategies are necessary in order to maintain a well-integrated personality. Gardner (1982) outlines a coping strategy that focuses on the attentional element in relieving the discomfort of tinnitus.

In the mid-thirties, discoveries linking vitamins and health encouraged the therapeutic use of vitamins for many different maladies (Brummett 1981). Tinnitus was one of the problems studied, and there are reports that both tinnitus and hearing loss benefited from the use of Vitamin B1. Vitamin A was also given to patients with auditory complaints and some clinical improvements were noted. By 1951, when Baron published his skeptical study about Vitamin A therapy, the vitamin craze had subsided. From time to time these therapies resurface, but controlled studies are not available. Vasodilators have also been tried for the relief of tinnitus and are considered to be possibly effective by the Food and Drug Administration. Controlled studies about these substances are presently under way.

Antidepressants are often prescribed for tinnitus patients who 
also suffer from depression. One of the unfortunate side effects of the tricyclic antidepressants is the exacerbation of tinnitus (Drucker, 1979).

In 1937 Lewy investigated the possible efficacy of local anesthetic agents for the relief of tinnitus. Quite recently interest in this possible treatment was revived when researchers observed that tinnitus patients indicated reduced or relieved tinnitus symptoms while receiving intravenous lidocaine treatment for other problems (Melding et al., 1978). Shortly thereafter a number of research centers started working with this and other related drugs (Shea \& Harrell, 1978, Donaldson, 1978, Emmett \& Shea, 1980, Israel et al., 1981). These researchers found that lidocaine does provide relief, albeit transient, for tinnitus and points the way to the development of a related substance that can be tolerated by the patient and provide long-lasting relief. Surgical procedures were advocated by some physicians who thought that sectioning the VIII nerve would eliminate the tinnitus along with the person'i hearing(Johnson,1954), but only a relatively small percentäc of thos patients upon whom this surgery was performed actually were relieved of the tinnitus. Far more often the patient lost his hearing yet retained the tinnitus (Green \& Douglass, 1951).

Biofeedback has recently become widely used for the treatment of some tinnitus patients, particularly those for whom other procedures have not proved effective. Benefits derived from this type of therapy include the learning of relaxation techniques, self awareness, and a general feeling of being more in control of bodily processes (House, 
1977).

In a more recent paper House (1981) described how patients appeared to divide into three groups. The first group, which she called depressive reaction, contained patients for whom tinnitus was a major problem along with depression. These patients benefited from treatment and obtained relief from their tinnitus when the depression was relieved. The second group, hysierical conversion or neurotic, contained patients who exhibited hysterical defenses and generally perceived their tinnitus problem as a physical one. They didn't understand the problem well and lacked insight into it. These patients obtained some relief with biofeedback treatment but not as much as the depressive group. The third group of patients, described as borderline, usually exhibited schizoid behaviors. These patients had more than one MMPI scale elevated beyond two standard deviations from the mean, and were difficult to treat.

Goodey(1981) indicated that in his New Zealand clinic he had administered personality inventories to 200 tinnitus patients and found that they appeared to have quite different personalities from pain patients. There was a low incidence of hypochondria and these patients did not seem to benefit from supportive treatment. He reported that 20 percent were depressed and eight percent were irritated by the tinnitus. His comment indicating lack of benefit from supportive treatment, i.e. counseling, is consistent with the observation by House and others that tinnitus patients have to be persuaded to seek counseling because they do not usually perceive their problem to be a psychological one. They 
will of ten try many kinds of medical and non-medical treatments before deciding that they need help in learning to cope with their tinnitus. Patients of ten report that psychological counseling is no': very helpful. Tinnitus is a real, physiological condition, and is usually perceived as such by the patient. Patients, therefore, are of ten reluctant to embark on a course of treatment that is insight-related rather than an active or visible procedure designed to bring relief.

Some patients have found that the hearing aids used to compensate for their hearing loss have been beneficial for the tinnitus as well. It is thought that the reason this is advantageous is that with the hearing aid, the ambient noises can be more easily perceived by the patient and the tinnitus, while still present, becomes less noticeable (Saltzman \& Ersner, 1947).

Perhaps the most successful method of treatment at this time is masking, a procedure involving the introduction of an external sound, closely matched to the frequency of the patient's tinnitus. Masking substitutes for, inhibits, or suppresses the internal sound of the tinnitus (Vernon \& Meikle, 1981). One is able to ignore or disregard external sounds far more easily than internal ones, and this is thought to be the reason that the masking is effective.

It seems that the traditional medical model in which diagnosis and treatment are based on etiology has not been entirely successful with tinnitus. In this model one first considers organic causes, specific pathologies, lesions, infections, and dysmetabolisms, and then makes diagnostic assumptions based on signs and symptoms, and finally plans 
treatment to destroy the pathological agent, alter the impaired function, or treat the uncoriscious determinant (Szasz, 1974). According to Szasz, deafness is phenomenological, a body sign. Should tinnitus be considered likewise, or is it more like pain, a suffering behavior? Treatments that deal with tinnitus as an organic symptom, such as masking and biofeedback, have proved more successful than insight-related psychotherapy.

In summary, it is evident that no single treatment procedure is appropriate for all tinnitus patients. However, it is encouraging that considerable research is being directed toward finding more effective procedures for dealing with this problem.

HEARING LOSS

\section{Psychological aspects of hearing loss}

Previous studies have established the fact that hearing loss often causes the affected person to have personality changes. These changes are thought to be a result of how the person perceives himself in his environment.

A recent study (Zimbardo, 1981) at Stanford University reveals that paranoia may develop because people are unaware of their distorted perception of reality. Temporary hearing loss was hypnotically induced in subjects in this study and they quickly developed symptoms of paranoia, both as perceived by the experimenters and as measured using standard personality measuring techniques. 
Myklebust(1960) points out that in studying the psychological effects of hearing loss, we must be aware of the sensory function of hearing. He defines hearing as the basic contact, scanning, and alerting sense and refers to it as the primary background sense. Even a moderate hearing loss seriously impairs the function of background hearing. When this background function is impaired, the individual is forced to give equal attention to all sound, causing that person necessarily to reorganize his perceptual thinking.

Ramsdiel ( 1960$)$ also addressed this issue when he wrote about the three psychological levels of hearing. Level 1, language comprehension, is the symbolic level. Level 2 is the sign or signal warning level. Level 3 is the auditory background level. This primitive level of hearing where we react to sounds that are in the background of our senses, establishes the foundation for our conscious experience. This constant reaction to the environment couples the individual with the living, active world. When a person is deprived of this primitive function, whether or not he realizes it, he may feel insecure or depressed or have a flat or deadened affect.

THE MINNESOTA MULTIPHASIC PERSONALITY INVENTORY

\section{Description and applications}

The Minnesota Multiphasic Personality Inventory (INPI) has been used to make reliable discriminations between patients with neurotic disorders, or anxiety disorders. It has been used to differentiate 
between patients with functional psychiatric and psychosomatic disorders in such areas as conversion disorders and early multiple sclerosis or diabetes, functional and organic impotence, and functional and organic back pain.

More than 20 years ago the MMPI was used to measure personality characteristics of hearing-impaired and deaf persons (Myklebust, 1960). These studies indicated a relationship between hearing Ioss and personality, with the most obvious and consistant results for those who sustained marked deafness in childhood. One of the questions addressed in that study was, "What kind of person is this and what are nis/her chances for improvement?" Generally speaking, the adjustment problems for a young adult who is deafened are considerably greater than those for an older adult who expects to lose his hearing. Life becomes more stressful in many ways. The deafened or hearing-impaired person becomes more dependent on his/her family. Inconveniences are experienced both at home and at work, friendships become strained and of ten are abandoned, and social isolation is markedly apparent. Even though hearing-impaired persons may state that their employers are fair and that their families are patient, many become despondent and eventually cynical toward those with normal hearing. The extent to which a person perceives his hearing impairment to be a handicap is a crucial factor in trying to interpret his attitudes as measured by a personality inventory (Mylkebust, 1960). Those patients who estimate their hearing loss to be a serious handicap would likely be more hypochondriacal. If the conditions really are a handicap, then these people would be "adjusted" because they correctly 
identify their problem. Conversely, those patients who do not consider hearing loss to be a serious handicap might have poor insight and greater emotional problems. Findings from Myklebust's study indicated that more unfavorable adjustment scores, as compared to the normal, existed in the population of hearing-impaired people. Myklebust did not interpret these results as indicative of true mental illness, but rather concluded that hearing loss imposes a personality restriction. He said that the way in which the deaf person interprets reality might be different from that of a normal-hearing person.

In the intervening years since this study great strides have been made in hearing-aid technology, and it is unlikely that a similar study made today would produce the same results.

The MMPI appears to be a suitable instrument for assessing the personality of the tinnitus patient. Personality is one of those terms that resists definition. The characterization that was being attempted in this study has to do with the response systems of individuals who suffer from a chronic problem, tinnitus. The MMPI allows assessment of a patient's responses along 13 dimensions, thus providing information about that person's orientation to societal norms. These dimensions can be more fully explored in the many texts and handbooks that are available about the MMPI.

Very briefly, the scales are designed to measure the following:

L Constructed to detect an attempt by the subject to present him/herself in a more favorable light.

E Developed to detect deviant or atypical responses to test items. 
K Reflects test-taking attitude. Measures same traits as $\underline{L}$ but more subtly.

LiHs Measures somatic concerns, symptoms usually associated with the label of hypochondriasis.

2:D Developed to assess symptomatic depression.

3:Hy Developed to identify patients utilizing hysterical reactions to stress situations.

4:Pd Broad scale that identifies patients diagnosed as psychopathic.

5iMf Originally developed to identify homosexual males this scale is now sometimes used as a male/female interest inventory.

6:Pa Used to identify patients with paranoid symptoms.

I:Pt Developed to measure symptomatic psychasthenia. A good index of psychological turmoil and discomfort.

8:Sc Developed to identify patients diagnosed as schizophrenic.

2:Ma A measure of hypomania (activity level, excitability, irritability, and grandiosity).

Q:Si Assesses subject's tendency to withdraw from social contacts.

The MMPI scores achieved by tinnitus patients appear to relate well to clinical observations and to other tests (House, 1977).

The MMPI was used by a group of medical researchers in Italy to assess personality in otosclerotic patients (Pizzichetta \& Ferraro, 1976, 1978). In the first study, 200 patients with similar personality profiles, 120 with otosclerosis, and 80 whose otosclerosis had been surgically treated were compared. The depression elevation was gone 
from the surgically treated patients. The authors indicated that MMPI profiles showed a tendency toward psychosis rather than actual psychosis in the two groups. In the second study, 150 patients with hearing loss and otosclerosis and 150 patients with conductive and perceptive losses were compared. Four main personality types were identified based on scores on three MMPI clinical scales. One type had normal MMPI scores. A second type had an elevated score on Scale $3: \mathrm{Hy}$ or Hysteria. A third type had an elevated score on Scale 2:D or Depression. The fourth personality type had an elevated score on Scale 8:Sc or Schizophrenia. The otosclerotic group was elevated on $\mathrm{Hy}$ and $\mathrm{D}$.

Two stidies measuring pre- and post-operative personality traits for patients with otosclerotic hearing problems indicated that the resolution of the hearing problem did cause scores on these personality measures to become more like those of normal individuals. In the Gildston and Gildston (1972) study, measurement was made using the Guilford-Zimmerman Temperament Survey. Seven traits were measured for comparison: Ascendance, Sociability, Emotional Stability, Objectivity, Friendliness, Personal Relations and Masculinity. All traits except masculinity and personal relations showed a significant decrement in pre-operative patients. All except masculinity showed a significant increment in post-operative patients. This study serves to identify the fact that individuals with hearing loss do differ in personality structure from the individual who has normal hearing. What is not reported is how pre-existing personality factors influence perceived problems created by the hearing loss. 
The second study by Jackson et al. (1971) reported on stapedectomy patients who were grouped according to whether they either did or did not report changes in interpersonal relationships due to hearing loss. The patients were treated to a battery of psychological and sensory measures resulting in conclusions that some differences were detectable. Significant differences were found between the two groups on the Clyde Mood Scales, the Kerle Subjective Stress Scale and the Berkun Subjective Hostility Scale, and the Eysenck Neuroticism Scale. The fact that patients with very similar hearing impairments had different perceived social effects of that impairment is an important aspect of the study.

More recently the MMPI was used to assess tinnitus patients in a group selected for biofeedback treatment (House, 1977). These patients had elevations on some of the scales, showing distinct personality problems with a high tendency toward either neurotic behavior or overt depression. The patients in this study had already tried most of the available forms of treatment for their tinnitus without notable success. At the time of the Houses's study there were practically no effective relief procedures available to the tinnitus patient.

It would appear from these studies that one could anticipate the tinnitus patient to have elevated scores on several of the MMPI scales. The question that will be addressed is whether there is any difference among the hearing- loss-with-tinnitus patient who perceives either the hearing loss or the tinnitus to be the greater problem, the tinnitus patient whose hearing is normal, and the person who has a hearing loss but is free of tinnitus. If differences are shown, then perhaps 
therapies can be found that will help those patients who find it difficult to cope with the problems of stress and tension that of ten accompany tinnitus. The individual's personality is an important mediator of life events, according to researchers such as Lieberman (1975) who, in reporting characteristics of adaptation in older adults, found that those elderly persons who were aggressive, narcissistic, demanding, and irritating were those individuals who were most likely to survive a crisis. If we can identify common personality traits in those tinnitus patients who are best able to cope, then perhaps we can help those who have difficulty with life situations. The question is, do tinnitus patients have a greater number of these problems than a non-tinnitus population? Is there a problem or group of problems common to tinnitus sufferers? Can a pathological level of affliction be identified? Can a specific collection of these problems be grouped together and called a "tinnitus personality"? If so, can this "tinnitus personalityn be predicted from scores on the MMPI? Does the treatment that is both recommended and followed for relief of the patient's tinnitus have an effect on personality? The following experimental design was proposed in an effort to answer some of these questions. 
CHAPTER III

METHODS

\section{Subjects}

The MMPI 168 Personality Inventory was administered to 146 subjects who comprised the four groups in this study. The sizes of the groups $r \epsilon^{n}$ est the frequency for each of those groups as they go through the Tinnitus Clinic. Group IV was a special case and was drawn from other populations in order to provide a coriparison group of patients who were free of tinnitus. Group I included 17 patients with tinnitus and no hearing loss. This group was composed of patients selected from the files at the Oregon Health Sciences University Tinnitus Clinic. These patients had to have had tinnitus for at least six months and have hearing levels which were $20 \mathrm{db} \mathrm{HL}$ or better in frequencies out to 3000 $\mathrm{Hz}$, and not greater than $30 \mathrm{~dB} \mathrm{HL}$ for frequencies above $3000 \mathrm{~Hz}$. If the patient's audiogram was more than six months old, he or she was retested by one of the audiologists or audiometric technicians at the Tinnitus Clinic. Subjects were required to nave an education level of at least high school or beyond in order to assure an understanding of the questions on the inventory. Minirnum age for inclusion was 18 years. The age range of patients in this group was from 24 to 66 years.

Group II was composed of 70 patients with both tinnitus and hearine loss where the patient preceived the tinnitus to be the greater problen. This group also was drawn from the files at the Oregon Health Sciences University Tinnitus Clinic. In order to be included as a research 
subject, an individual in this group was defined as having a hearing loss if his or her present audiogram indicated a loss in excess of $30 \mathrm{~dB}$ HL for frequencies of $3000 \mathrm{~Hz}$ and above, or more than $25 \mathrm{~dB} \mathrm{HL}$ across frequencies. These subjects had to have had tinnitus for at least six months. The age range of patients in group II was from 25 to 77 years. Education criteria were the same as for group I.

Group III included 44 patients with both tinnitus and hearing loss where the patient perceived the hearing loss to be the greater problem. This group was drawn from the patient population of the Oregon Health Sciences University Tinnitus Clinic. The age range of patients in group III was from 19 to 80 years. Tinnitus, hearing loss, and education criteria were the same as for group II.

Group IV consisted of 15 patients with a hearing loss but who did not report having tinnitus. These patients were drawn from the patient population of the Portland Center for Hearing and Speech, from the patient population of the Ear Nose and Throat Clinic of the Oregon Health Sciences University (ENT-OHSU), and from the private patients of a local hearing-aid dispenser who works closely with the Tinnitus Clinic. These patients were identified as having hearing losses similar to those in groups II and III, but who did not report having tinnitus. Reports of transitory tinnitus, not bothersome to the patient, was considered as no tinnitus. The age range of patients in Group IV was from 45 to 92 years. Education requirements were the same as for the previous groups.

It was not possible to equalize the numbers of men and women in the 
study because the patient population of the Tinnitus clinic is predominantly male.

\section{Test instrument}

The test that was administered, the MMPI 168, is a shortened version of the MPI. This inventory is composed of the first 168 items of the standard MMPI and is scored in exactly the same way as the full MMPI on those first 168 iters. The booklet form of the MMPI was used along with an answer sheet that was to be marked in pencil. Scoring was done manually from templates using the items indicated by Graham (1981). The MMPI is an empirically derived, self-report scale. It is the most widely used of the objective measures of personality. The original inventory of 566 items has been found to be longer than is convenient for many clinical situations and as a consequence a number of shorter forms have been devised. The MMPI 168 appears to have as good reliability and validity as the longer version. Gynter and Gynter (1976) have reported that the MMPI is among the most reliable of all psychological tests. The person taking the test will give similar answers each time. The person scoring the inventory can do so accurately, and the person interpreting MMPI profiles can make these interpretations according to established decision rules. However, Anastasi (1976) reports retest reliabilities from the MMPI manual that range from the $.50^{\prime} \mathrm{s}$ to the low $.90^{\prime} \mathrm{s}$. She further isicicates that the high intercorrelation of the scales and the variability of behavior assessed on some scales (notably scale 2-Depression), render retest 
reliability inappropriate. The MMPI has proved to be most valuable when used to make gross distinctions between people or groups of people. A somewhat more skeptical view is held by many psychologists about its clinical utility. The MMPI, and other personality tests, can be expected to show large subcultural and cultural differences. A knowledge of the general demographic variables in our sample was provided from the clinic questionnaires, or in the case of patients recruited from other agencies, from an additional questionnaire at the time they took the MMPI.

\section{Test Procedure}

Patients of the Tinnitus Clinic were mailed the MMPI questionnaire and asked to complete it and bring it with them at the time of their clinic appointment. Patients from the Speech and Hearing Center, the OHSU-ENT clinic, or from the hearing-aid dispenser were invited to participate in the study either at the time of their appointment or with

a personal request from the investigator. They were provided with a pre-stamped addressed envelope in which to return the completed questionnaire. The patients who participated were offered a short synopsis of the findings of this investigation which was mailed to them upon completion of the study.

The tinnitus clinic records of the participating patients were examined in order to determine the patient's age, employment, perception of the severity of his or her problem, and whether tinnitus or hearing loss was causing the greatest difficulty. The record also contained the 
patient's audiogram and audiological report from which group placement could be determined. Similar information was available from the other clinics and the dispenser participating in the study.

Patients coming to the tinnitus clinic were evaluated for hearing problems as well as for tinnitus. They were asked to complete a questionnaire about their tinnitus, hearing problems and medical history. This questionnaire and the MMPI questionnaire were generally brought in by the patient at the time of the appointment.

An audiogram was derived using standardized procedures and the tinnitus was measured using a tinnitus synthesizer. Sounds and combinations of sounds were presented to the patients for comparison with their tinnitus. In addition to the evaluation under earphones, actual instruments were tried on the patients to determine whether masking and/or amplification could be used to relieve the tinnitus and/or the hearing problem if there was one.

Patients received counseling from the audiologist about their hearing and/or tinnitus problem and were cautioned to avoid noise exposure and certain medications known to exacerbate tinnitus.

In spite of these objective measures, the phenomenon of tinnitus still remains a highly complex and individual experience whose etiology often eiudes both the patient and the clinician. A person's expectations about the symptom, how he or she perceives the symptom as a problem, and his or her interpretation of its personal meaning influences the extent to which an objective report can reflect a true picture of the patient's distress. Some people who are depressed, 
hysterical, hypochondriacal, or self-centered, require little if any organic pathology in order to produce symptomatic behaviors.

This research project was not expected to treat the patient's psycholvoical problem. Its purpose was to attempt to establish that tinnitus is often associated with a psychological problem.

Statistical analysis

Analysis of the data was carried out on the basis of four groups and 15 variables. The groups were the four specified earlier, and the variables were the 13 MMPI scales plus age and sex.

In order to determine whether the expected patterns of relationships could be discerned in the data, the hypothesis was tested using discriminant analysis. This is a procedure which allows the study of the differences between groups on each of the variables. The discriminant function is established using mathematical weights that maximize the differences between groups and systematically processes each of the variables so that each variable or combination of variables can be described along these functions, thus determining the relative importance of each variable. As in the simple analysis of variance, the discriminant criterion is the ratio of thebetween-groups sum-of-squares to its within-groups sum-of-squares. Discriminant scores are obtained and plotted for each group in the form of a scatterplot based on the first two discriminant functions (there are only three discriminant functions when one has four groups) allowing one to compare visually the distribution of scores likely to be found in each group membership. 
Predictions are derived and group membership is plotted on the basis of probabilty. Percentages of correct classification are given.

The SPSS program "Discriminant" was invoked on the Honeywell computer at Portland State University. Output from this progran provided 10 statistics for analysis: (a) Means; (b) Standard deviations; (c) Pooled within-groups covariance matrix; (d) Pooled within-groups correlation matrix; (e) Matrix of pairwise $E$ ratios; (f) Univariate $E$ ratios; (g) Tests for equality of group covariance matrices; (h) Group covariance matrices; (i) Total covariance matrix; and (j) Structure matrix (pooled within-groups correlation between the canonical discriminant functions and the discriminating variables).

The data were further examined using the SPSS program "Oneway." This program provides an analysis of variance and also allows one to make apriori comparisons between groups for each of the dependent variables.

As the data were collected, preliminary analysis using $t$ tests, Chi squares, and $E$ tests were done to determine at what point the data would appear to stabilize. These tests were performed after data had been collected on a total of 25,50 and 76 patients. At this point the two larger groups(groups II and III) contained approximately 40 and 30 patients and were thought to be an adequate sample. Groups I and IV, still containing less than 10 patients each, were not. When group size exceeded 10 , results appeared to stabilize. 
Preliminary tests yielding $E$ and $\frac{t}{2}$ statistics, indicated the need to perform the more complex analysis found in the discriminant program. The results of these findings will be discussed in the next chapter. 


\section{CHAPTER IV}

\section{RESULTS AND DISCUSSION}

The hypothesis guiding this study states that there are personality characteristics that would differentiate the patient for whom tinnitus is the greatest problem from the patient who suffers from hearing loss alone or who perceives his hearing loss to be a greater problem than his tinnitus.

In order to determine these personality characteristics, a multifaceted personality inventory, the MMPI, was administered to the four groups of patients defined in the previous chapter.

A number of statistical procedures were employed that allowed examination of the data in hopes of answering the following research questions:

1) Are there significant differences between the scores on the various scales of the MMPI for Groups I and II vs. Groups III and IV?

2) Are there significant differences between the scores on the various scales of the MMPI for Group II and Group III?

3) Is it possible to select scales which will differentiate between these four groups?

4) Are there general statements that can be made about the tinnitus clinic population? 
Previous studies indicate that there may be elevations for the hearing- loss patients on scales 2(Depression), 8(Schizophrenia), and O(Social introversion)(Myklebust, 1960), and for tinnitus patients on scales 1(Hypochondriasis), 2(Depression), 8(Schizophrenia), and 9(Hypomania)(House, 1977 and personal communication).

Means and standard deviations were calculated for all of the scales. From these data mean profiles were drawn for each of the four groups. These data are shown graphically in Figure 1. Expressing the data in this way has the disadvantage of averaging out certain characteristics, especially where there is a large variation in the scores among the subjects in a given group. It was possible, however, to make some comparisons between the groups. The mean score profile for Group I, for instance, can be seen to lie some distance from the other profiles. The interpretation of MMPI profiles of ten involves clinical judgment. There are certain accepted generalizations that are employed in this interpretation and these are readily available in the literature. The results for each group will be reported and discussed individually.

Group Ii Patients with tinnitus and normal hearing sensitivity.

The test-score means and standard deviations for each of the 13 MMPI scales for Group I patients are reported in Table I. The mean results are also shown graphically in Figure 2. Inspection of the raw data for this group showed that $82 \%$ of these patients had elevated scores on one or more scales. 


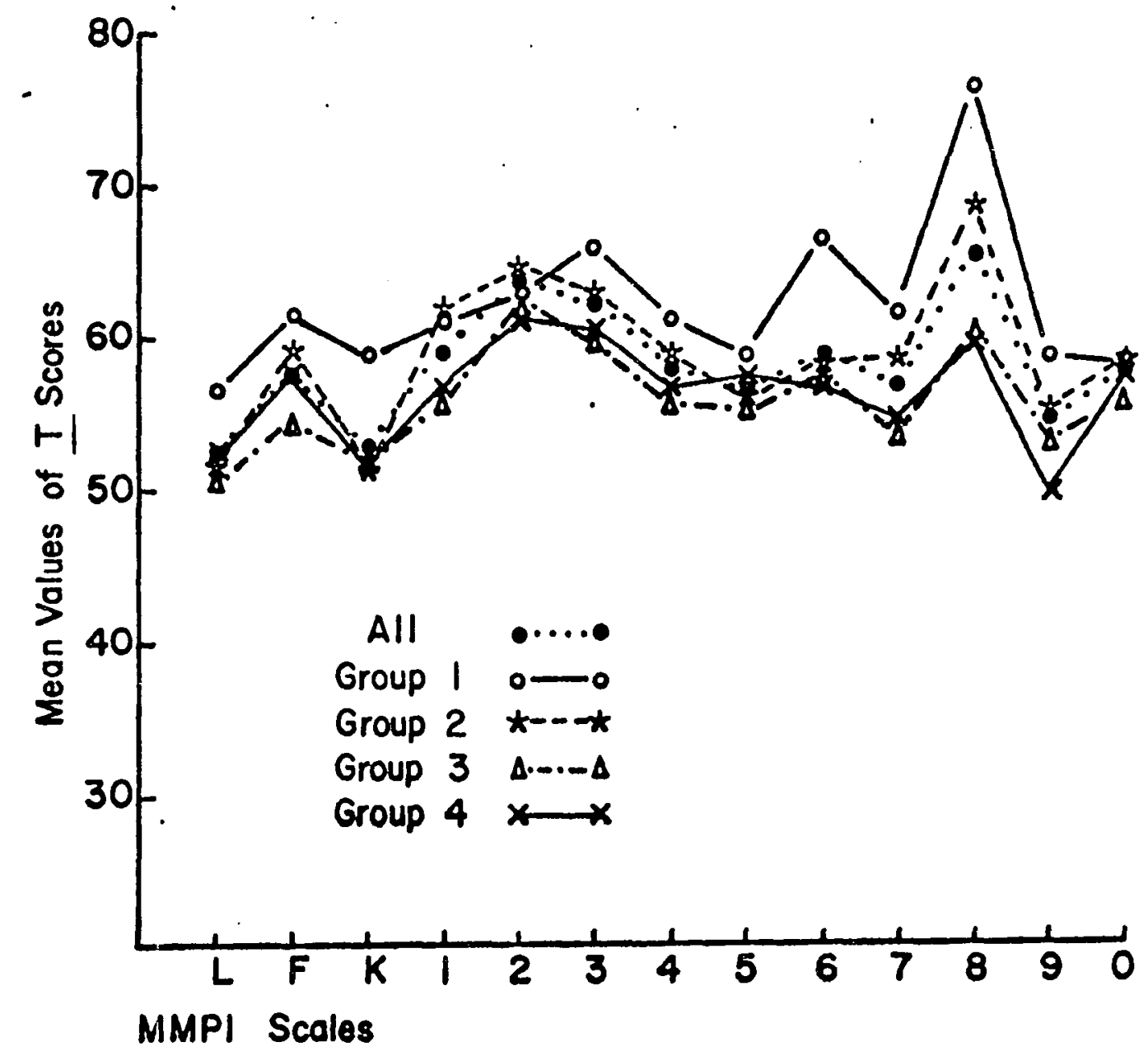

$x$

$\hat{\beta}$

-

AGE

Figure 1. Age means and mean values of MMPI T scores for all groups. 
The MMPI scores are I scores having a mean of 50 and a standard deviation of 10 . One mean score exceeded 70 and six others were greater than 60. A I score of 70 or above is generally regarded as a sign of poor adjustment based on the factor of that particular scale (Gallagher, 1953). Only scale 8(Sc), had a mean score that was more than two standard deviations above the mean. There are, however, apparent tendencies toward elevation on the neurotic triad(Scales $1,2,3)$ and on the two psychotic Scales 6 and 7 , and a definite elevation on the psychotic scale 8. In addition, this group shows an inverted ' $v$ ' configuration in the validating scales. When evaluating groups of psychiatric patients, this shape would indicate presence of psychopathology and a recognition of this state by the patient. Graham(1977) characterizes this type of patient as being overly self-critical and/or exaggerating his or her problems. In this group of essentially normal patients the inverted ' $v$ ' may merely be signaling the "cry for help" or the attempt to bring attention to their disturbance. As previously mentioned, the high score for this group was Scale 8 followed by Scale 6 and Scale 3. According to Lanyon(1968), high scores on scale 8 by normal patients often indicate anxiety, internal conflict, withdrawal, emotional isolation, and nonconformity. When the result is modified by elevation on scale 6 , one might also see an excessive personal sensitivity, rigidity, or feelings of persecution. The addition of an elevated Scale 3 for Group I indicates a tendency toward some specific somatic complaint or symptom, particularly when under psychological stress. 
TABLE I

MMPI I SCORE MEANS AND STANDARD DEVIATIONS

EOR GROUP I, PATIENTS WITH TINNITUS

AND NORMAL HEARING

\begin{tabular}{|c|c|c|c|}
\hline \multicolumn{2}{|c|}{ Scale } & \multicolumn{2}{|c|}{$\begin{array}{l}\text { Mean } \\
\text { Standard Deviation }\end{array}$} \\
\hline & L & $\begin{array}{l}M \\
S D\end{array}$ & $\begin{array}{r}56.41 \\
9.62\end{array}$ \\
\hline & $E$ & $\begin{array}{l}\mathrm{M} \\
\mathrm{SD}\end{array}$ & $\begin{array}{l}61.35 \\
11.46\end{array}$ \\
\hline & $\mathrm{K}$ & $\begin{array}{l}M \\
S D\end{array}$ & $\begin{array}{r}58.94 \\
7.57\end{array}$ \\
\hline 1 & Hy & $\begin{array}{l}\mathrm{M} \\
\mathrm{SD}\end{array}$ & $\begin{array}{l}61.00 \\
14.82\end{array}$ \\
\hline 2 & D & $\begin{array}{l}M \\
S D\end{array}$ & $\begin{array}{l}63.53 \\
12.93\end{array}$ \\
\hline 31 & $\mathrm{Hs}$ & $\begin{array}{l}M \\
S D\end{array}$ & $\begin{array}{r}65.71 \\
9.12\end{array}$ \\
\hline 41 & $\mathrm{Pd}$ & $\begin{array}{l}M \\
S D\end{array}$ & $\begin{array}{r}60.76 \\
9.94\end{array}$ \\
\hline 51 & Mf & $\begin{array}{l}M \\
S D\end{array}$ & $\begin{array}{l}58.41 \\
14.01\end{array}$ \\
\hline 61 & $\mathrm{~Pa}$ & $\begin{array}{l}M \\
S D\end{array}$ & $\begin{array}{l}66.06 \\
13.70\end{array}$ \\
\hline 7 & $\mathrm{Pt}$ & $\begin{array}{l}M \\
S D\end{array}$ & $\begin{array}{l}61.59 \\
16.75\end{array}$ \\
\hline 8 & $\underline{S c}$ & $\begin{array}{l}M \\
S D\end{array}$ & $\begin{array}{l}76.12 \\
24.00\end{array}$ \\
\hline 9 & $\mathrm{Ma}$ & $\begin{array}{l}M \\
S D\end{array}$ & $\begin{array}{l}58.12 \\
13.25\end{array}$ \\
\hline 0 & Si & $\begin{array}{l}M \\
S D\end{array}$ & $\begin{array}{l}57.65 \\
11.23\end{array}$ \\
\hline
\end{tabular}




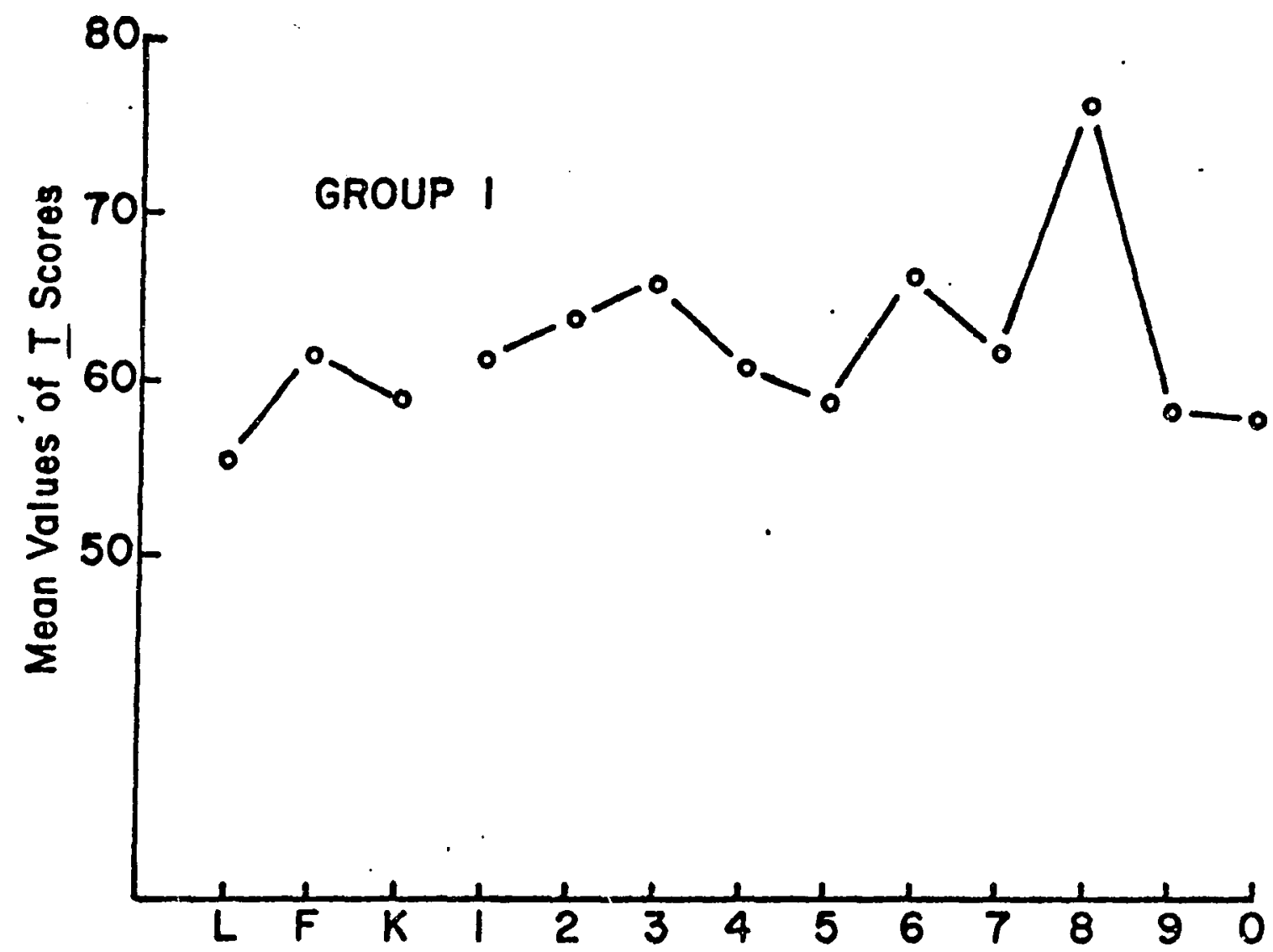

MMPI Scales

Figure 2. Mean values of MPI $T$ scores for Group I. 
This may be accompanied by self-pity and a cendency to place the blame on others for their own problems.

In reviewing the way the tinnitus patients answered the items on the MMPI that caused them to display these elevated profiles it was found that some of the items causing these elevations would have to be considered as logical and thoughtful responses on the part of the patient. For example, one who has an internal unrelenting noise in his or her head would quite logically answer true to item number 32: "I find it hard to keep my mind on a task or job". This example points out something that must be kept in mind and that is that while the MMPI appears to be able to differentiate between groups of patients who have tinnitus and perhaps other disorders as well, the MMPI is not able to provide causal information on these patients. It cannot be determined on the basis of the MMPI whether the tinnitus is causing the patient to have problems with life situations or whether people who have psychopathology are also predisposed to tinnitus.

Combining these findings for Group I, a typical patient with tinnitus and no hearing loss might be characterized. This patient will usually be younger than 50 , and will be very concerned and anxious about the tinnitus--often to the point of having made some changes in social and personal relationships. This patient is likely to be unsatisfied with the attempts he or she has made to seek help for the tinnitus. In seeking an answer to his or her problem of head noise, he or she may have been subjected toa wide battery of medical tests. 
Often this extensive testing, rather than setting the patient at ease about his problem, serves to confuse and excite him and cause him to worry that something is seriously wrong and perhaps even life-threatening. A considerable amount of stress will be observable and/or self-reported. There may be patients in this group and in the sther tinnitus groups who do not respond to treatment. Tinnitus is not usually a problem for which patients seek psychotherapy, and consequently psychiatrists and psychologists are not as familiar with it as they are with those problems more commonly treated by them. In addition, the House study (1981) characterized some of the patients as being borderline personalities who were not responsive to treatment.

Group II: Patients whose orimary complaint is tinnitus but who also have a hearing loss.

Test-score means and standard deviations for Group II are shown in Table II. Mean results are also shown graphically in Figure 3.

It appears that the results of the tests with Group II have been somewhat modified because these patients also have a hearing loss. The scores mostly follow the same pattern as Group I but are lower. Only 63\% of these patients had an elevated or "poorly adjustedn score (see Table VI). Peak elevations for Group II appeared on Scales 8, 2, and 3 . It was expected that an elevation would be seen on the depression scale (Scale 2) after Myklebust's studies (1960) reported that hard-of-hearing patients scored high on the depression scale. 
TABLE II

MMPI I SCORE MEANS AND STANDARD DEVIATIONS FOR GROUP II, PATIENTS WHO HAVE HEARING LOSS AND TINNITUS, TINNITUS BEING THE PRIMARY COMPLAINT

\begin{tabular}{|c|c|c|}
\hline SCALE & \multicolumn{2}{|c|}{$\begin{array}{l}\text { Means } \\
\text { Standard Deviations }\end{array}$} \\
\hline L & $\begin{array}{l}M \\
S D\end{array}$ & $\begin{array}{r}52.06 \\
7.83\end{array}$ \\
\hline$E$ & $\begin{array}{l}M \\
S D\end{array}$ & $\begin{array}{l}58.77 \\
10.40\end{array}$ \\
\hline $\mathbf{K}$ & $\begin{array}{l}M \\
S D\end{array}$ & $\begin{array}{r}51.45 \\
8.16\end{array}$ \\
\hline $1 \mathrm{Hy}$ & $\begin{array}{l}\mathrm{M} \\
\mathrm{SD}\end{array}$ & $\begin{array}{l}61.27 \\
14.56\end{array}$ \\
\hline $2 \mathrm{D}$ & $\begin{array}{l}M \\
S D\end{array}$ & $\begin{array}{l}64.67 \\
14.31\end{array}$ \\
\hline 3 Hs & $\begin{array}{l}M \\
S D\end{array}$ & $\begin{array}{l}62.96 \\
11.54\end{array}$ \\
\hline $4 \mathrm{Bd}$ & $\begin{array}{l}M \\
S D\end{array}$ & $\begin{array}{l}58.93 \\
12.06\end{array}$ \\
\hline $5 \mathrm{Mf}$ & $\begin{array}{l}M \\
S D\end{array}$ & $\begin{array}{l}56.24 \\
12.00\end{array}$ \\
\hline $6 \mathrm{~Pa}$ & $\begin{array}{l}M \\
S D\end{array}$ & $\begin{array}{l}58.34 \\
15.19\end{array}$ \\
\hline 7 是 & $\begin{array}{l}\mathrm{M} \\
\mathrm{SD}\end{array}$ & $\begin{array}{l}58.21 \\
16.06\end{array}$ \\
\hline $8 \mathrm{sc}$ & $\begin{array}{l}M \\
S D\end{array}$ & $\begin{array}{l}68.30 \\
22.17\end{array}$ \\
\hline 9 쓰 & $\begin{array}{l}M \\
S D\end{array}$ & $\begin{array}{l}54.78 \\
11.68\end{array}$ \\
\hline $0 \underline{S i}$ & $\begin{array}{l}M \\
S D\end{array}$ & $\begin{array}{r}58.14 \\
9.60\end{array}$ \\
\hline
\end{tabular}




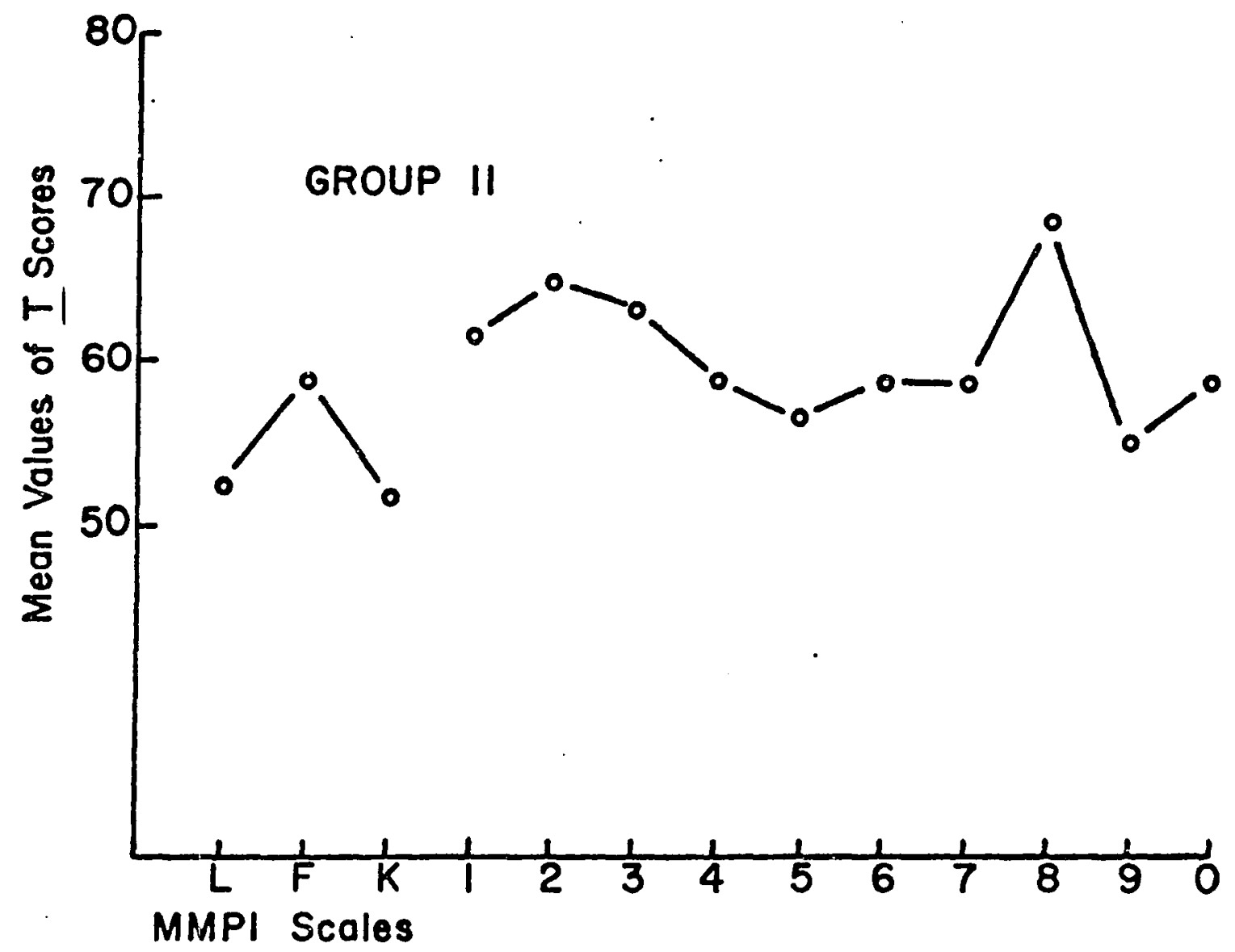

Figure 3. Mean values of MMPI T scores for Group 11 . 
It was also observed that patients frequently reported feeling depressed about their tinnitus. However, the profile indicates the same sort of pattern as was evident for Group I. The performance anxiety demonstrated by the elevation of scale 8 is amplified for this group by the addition of an elevated scale 2. It was expected that the typical patient in this group would be worried and somewhat pessimistic about getting help for his or her condition. These elevations, combined with an elevated scale 3, may also indicate a more typically neurotic patient, agitated and troubled by somatic complaints. These somatic concerns seem to override the more general social concerns seen with the elevated Scale 6 score for Group I patients. Furthermore, the moderate elevations seen in these patients on the depression scale are encouraging in that they tend to indicate that the patient recognizes his problem and may be motivated to initiate change.

Group III, Patients who are chiefly troubled by hearing loss but who also have tinnituse

Means and standard deviations for the MMPI scales are reported for this group in Table III. The mean results are also shown graphicaliy in Figure 4. Fifty-seven percent of these patients had scores above 70 on one or more scales. Visual inspection of the data for this group reveals elevations on Scales 2,8 , and 3 . These are the same elevated scores found for Group II. Mean scores in this group fall entirely between $T$-score levels 50 and 60 , indicating a relatively normally adjusted group. The mean age for patients in this group was 54.9 years, 
very close to the overall mean of the study, 54 years. Age has not been shown to modify MMPI scores to a great degree, although there is some evidence that younger people will score higher on the anxiety/activity Scales $4,8,9$, whereas older people will score higher on the internalizing/health preoccupation scales $2,3,0$. It is likely that the hearing loss suffered by members of this group has been developing over a number of years, and chances are good that they have acquired skills for coping with the hearing problem that are also useful. in coping with tinnitus. Those whose scores fall into the "disturbedn category are likely to be classified as neurotic.

Group IV: Patients whe suffer a hearing loss but not tinnituse

Means and standard deviations for this group are reported in Table IV. Graphic representation of the means is shown in Figure 5 . Profiles obtained for this group remain in the normal area although $60 \%$ of these patients show elevations of 70 or more on at least one MMPI scale. Table VI summarizes this information. The slight elevations on Scales 2 and 3 indicate that these are people who are concerned about somatic complaints. The greater age mean for this group, 65.67 , might also account for this tendency. Scale 8 was elevated less than for the other groups but still showed a small peak indicating some anxiety. The patients in this group were a more diversified sample in that they were not all actively seeking help for their hearing loss. Some of them had a long-standing hearing loss that was adequately compensated by the use of hearing aids. 
TABLE III

MMPI I SCORE MEANS AND STANDARD DEVIATIONS FOR

GROUP III, TINNITUS PATIENTS WHOSE PRIMARY COMPLAINT IS THEIR HEARING LOSS

\begin{tabular}{|c|c|c|c|}
\hline \multicolumn{2}{|c|}{ SCALE } & \multicolumn{2}{|c|}{$\begin{array}{l}\text { Mean } \\
\text { Standard Deviation }\end{array}$} \\
\hline & L & $\begin{array}{l}M \\
S D\end{array}$ & $\begin{array}{r}51.50 \\
7.84\end{array}$ \\
\hline & $E$ & $\begin{array}{l}M \\
S D\end{array}$ & $\begin{array}{r}54.50 \\
7.30\end{array}$ \\
\hline & $\mathbf{K}$ & $\begin{array}{l}\mathrm{M} \\
\mathrm{SD}\end{array}$ & $\begin{array}{r}52.86 \\
9.61\end{array}$ \\
\hline 11 & HS & $\begin{array}{l}M \\
S D\end{array}$ & $\begin{array}{l}55.64 \\
11.20\end{array}$ \\
\hline 2 & D & $\begin{array}{l}M \\
S D\end{array}$ & $\begin{array}{l}61.61 \\
14.10\end{array}$ \\
\hline & Hy & $\begin{array}{l}M \\
S D\end{array}$ & $\begin{array}{l}59.68 \\
10.22\end{array}$ \\
\hline & $\mathrm{Pd}$ & $\begin{array}{l}M \\
S D\end{array}$ & $\begin{array}{r}55.36 \\
7.74\end{array}$ \\
\hline & Mf & $\begin{array}{l}M \\
S D\end{array}$ & $\begin{array}{l}55.52 \\
12.45\end{array}$ \\
\hline 61 & $\mathrm{~Pa}$ & $\begin{array}{l}M \\
S D\end{array}$ & $\begin{array}{l}57.48 \\
10.40\end{array}$ \\
\hline 7 & Pt & $\begin{array}{l}M \\
S D\end{array}$ & $\begin{array}{l}53.38 \\
16.44\end{array}$ \\
\hline 8 & Sc & $\begin{array}{l}\mathrm{M} \\
\mathrm{SD}\end{array}$ & $\begin{array}{l}60.68 \\
19.54\end{array}$ \\
\hline & $\mathrm{Ma}$ & $\begin{array}{l}M \\
S D\end{array}$ & $\begin{array}{l}52.75 \\
12.56\end{array}$ \\
\hline 0. & Si & $\begin{array}{l}\mathrm{M} \\
\mathrm{SD}\end{array}$ & $\begin{array}{l}55.80 \\
11.13\end{array}$ \\
\hline
\end{tabular}




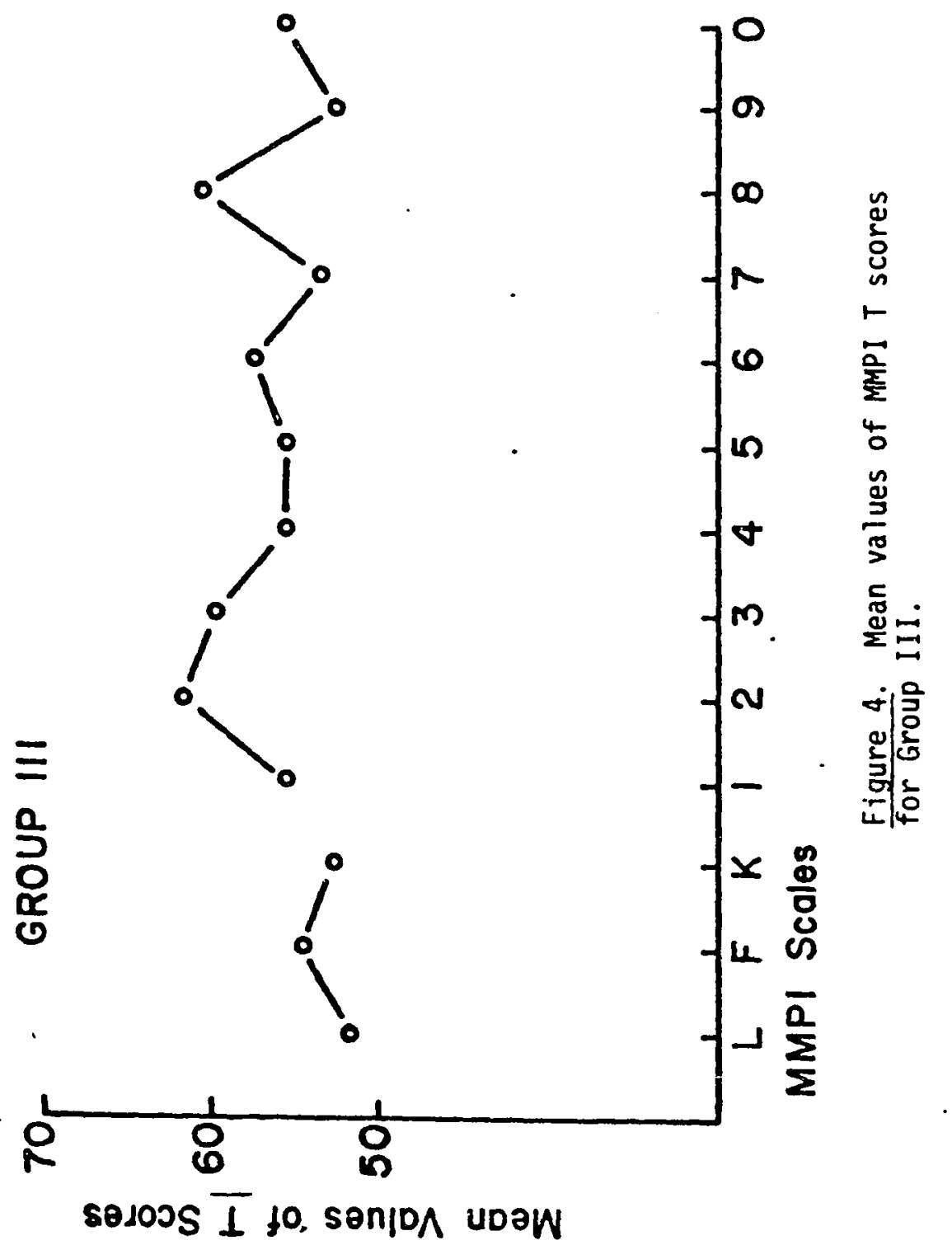


The figures for Group IV did, however, closely parallel those of Myklebust(1960), which indicated that they represent a valid sampling of hard-of-hearing people (see Tables V \& VI).

One final statistic that would appear to be of interest to the reader concerns the possible differences between male and female patients. An earlier study by Myklebust (1960) found that men with hearing losses tend to have a more difficult time adjusting to their problem than do their female counterparts. Table $V$ reveals means and standard deviations for Myklebust's population and for the three groups (II, III, \& IV) in the present study who exhibit a hearing disorder. Comparison of the scores indicate similar results for the two studies (see Figures 4,5 , \& 6). When the results were compared statistically, utilizing a test for significance of difference between proportions, no significant difference was found between the groups. Significant differences were noted between the studies when the elevated scores of females were considered (see Table VI). These elevations are not unexpected due to the changed role of women during those years. Notice that where the number of elevations exceeds four, both men and women today show more high scores than they did in 1960 . 
TABLE IV

MMPI I SCORE MEANS AND STANDARD DEVIATIONS

FOR GROUP IV, PATIENTS WITH HEARING LOSS

BUT NOT TINNITUS

\begin{tabular}{|c|c|c|}
\hline \multirow{2}{*}{$\begin{array}{c}\text { SCALE } \\
L\end{array}$} & \multicolumn{2}{|c|}{$\begin{array}{l}\text { Mean } \\
\text { Standard Deviation }\end{array}$} \\
\hline & $\begin{array}{l}M \\
S D\end{array}$ & $\begin{array}{r}52.93 \\
8.25\end{array}$ \\
\hline$E$ & $\begin{array}{l}M \\
S D\end{array}$ & $\begin{array}{r}58.07 \\
7.43\end{array}$ \\
\hline K & $\begin{array}{l}M \\
S D\end{array}$ & $\begin{array}{r}51.60 \\
7.50\end{array}$ \\
\hline $1 \mathrm{Hs}$ & $\begin{array}{l}M \\
S D\end{array}$ & $\begin{array}{l}56.07 \\
10.70\end{array}$ \\
\hline $2 \mathrm{D}$ & $\begin{array}{l}M \\
S D\end{array}$ & $\begin{array}{l}61.47 \\
19.04\end{array}$ \\
\hline $3 \mathrm{Hy}$ & $\begin{array}{l}M \\
S D\end{array}$ & $\begin{array}{l}60.47 \\
11.05\end{array}$ \\
\hline $4 \mathrm{Pd}$ & $\begin{array}{l}M \\
S D\end{array}$ & $\begin{array}{l}56.73 \\
13.55\end{array}$ \\
\hline $5 \mathrm{Mf}$ & $\begin{array}{l}M \\
S D\end{array}$ & $\begin{array}{l}57.07 \\
13.74\end{array}$ \\
\hline $6 \mathrm{~Pa}$ & $\begin{array}{l}M \\
S D\end{array}$ & $\begin{array}{l}56.87 \\
10.18\end{array}$ \\
\hline 7 Pt & $\begin{array}{l}M \\
S D\end{array}$ & $\begin{array}{l}54.47 \\
17.34\end{array}$ \\
\hline $8 \underline{S c}$ & $\begin{array}{l}M \\
S D\end{array}$ & $\begin{array}{l}60.40 \\
17.39\end{array}$ \\
\hline $9 \mathrm{Ma}$ & $\begin{array}{l}M \\
S D\end{array}$ & $\begin{array}{l}49.67 \\
12.98\end{array}$ \\
\hline $0 \Omega i$ & $\begin{array}{l}\mathrm{M} \\
\mathrm{SD}\end{array}$ & $\begin{array}{l}57.07 \\
i 1.18\end{array}$ \\
\hline
\end{tabular}




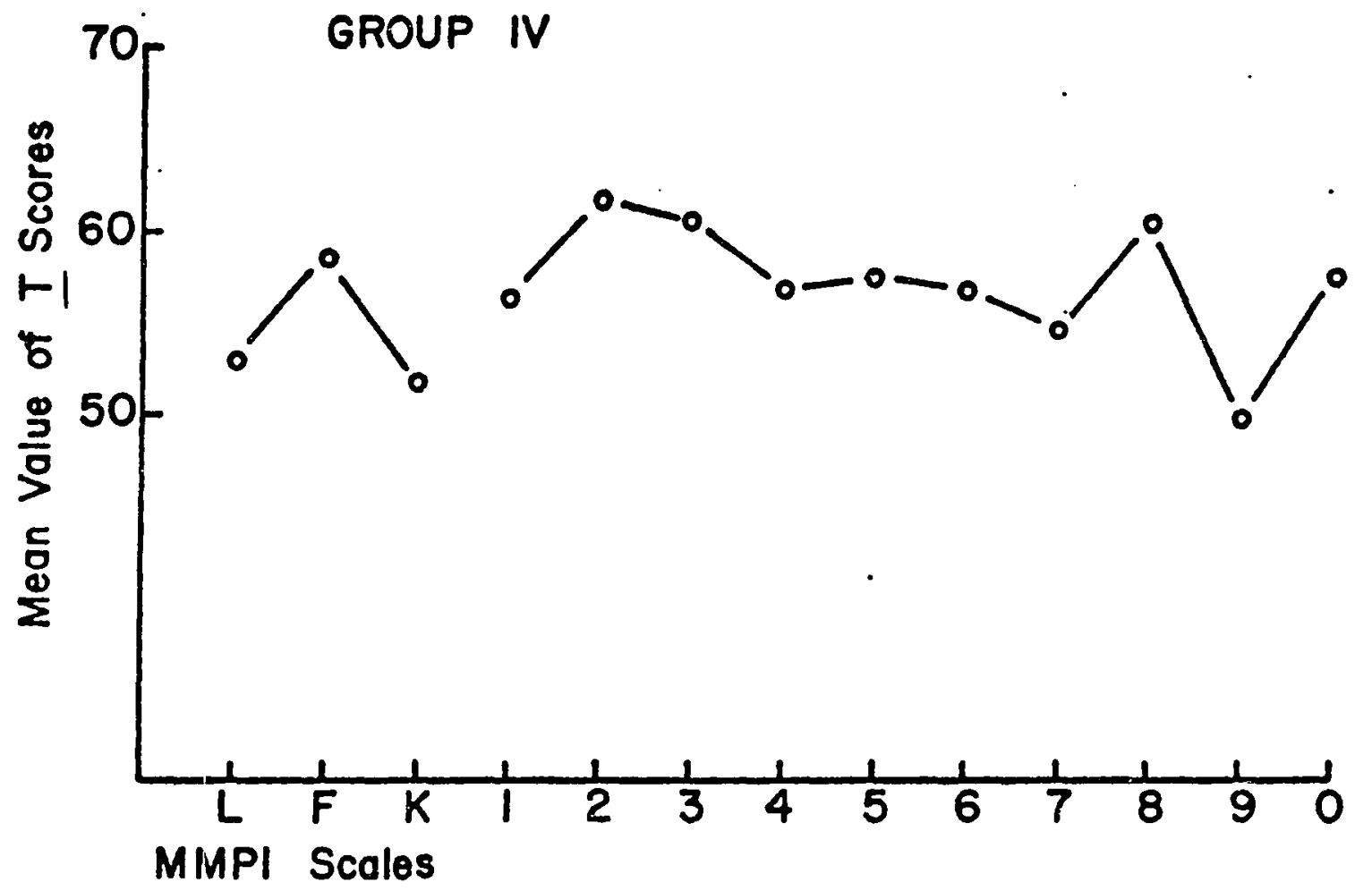

Figure 5. Siean values of MMPI T scores for Group IV. 
TABLE V

COMPARISON OF THE GROUPS WITH HEARING LOSS, GROUPS II, III and IV, WITH DATA PRESENTED

ON HARD-OF-HEARING INDIVIDUALS

BY MYKLEBUST ( 1960)

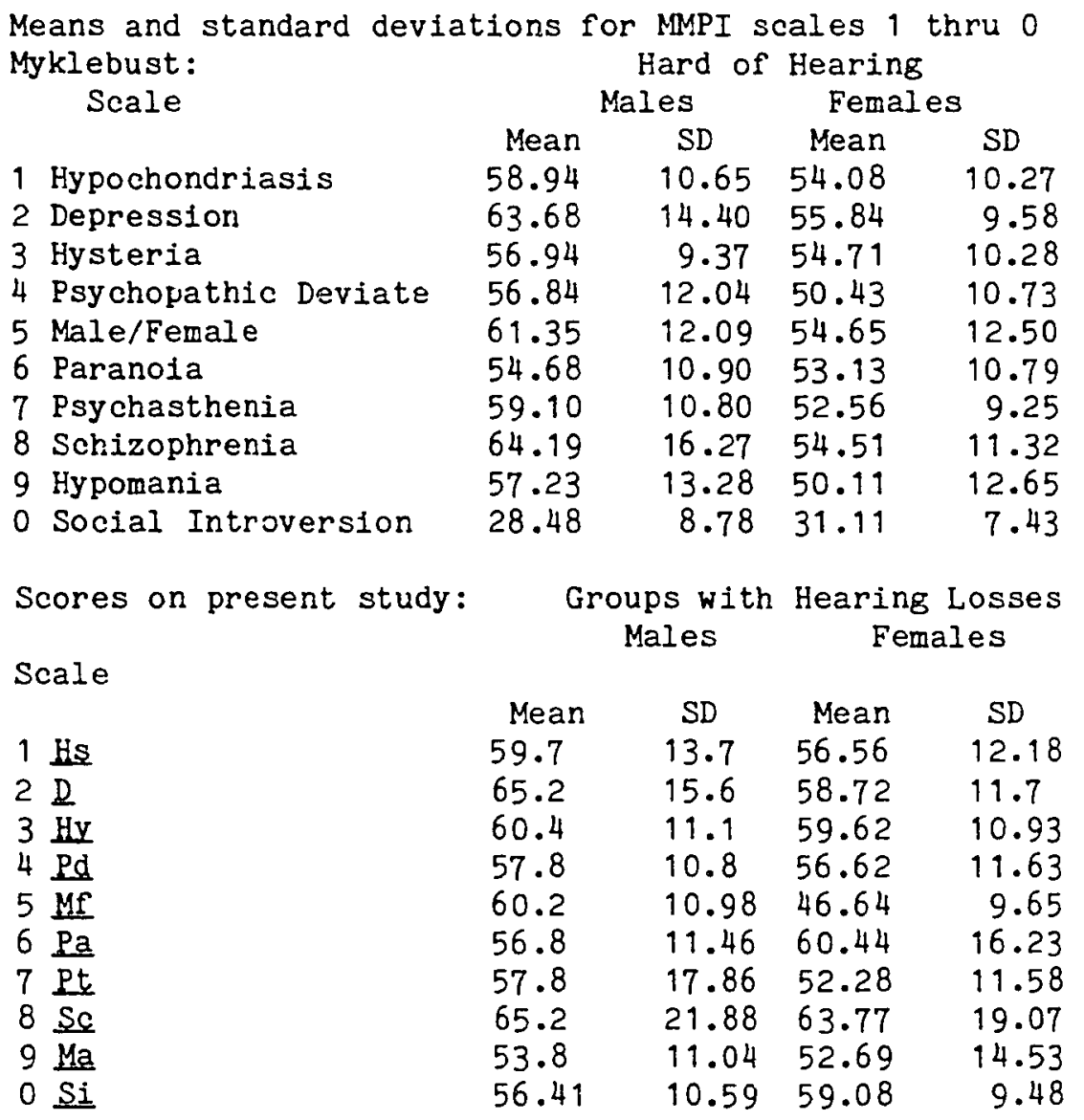




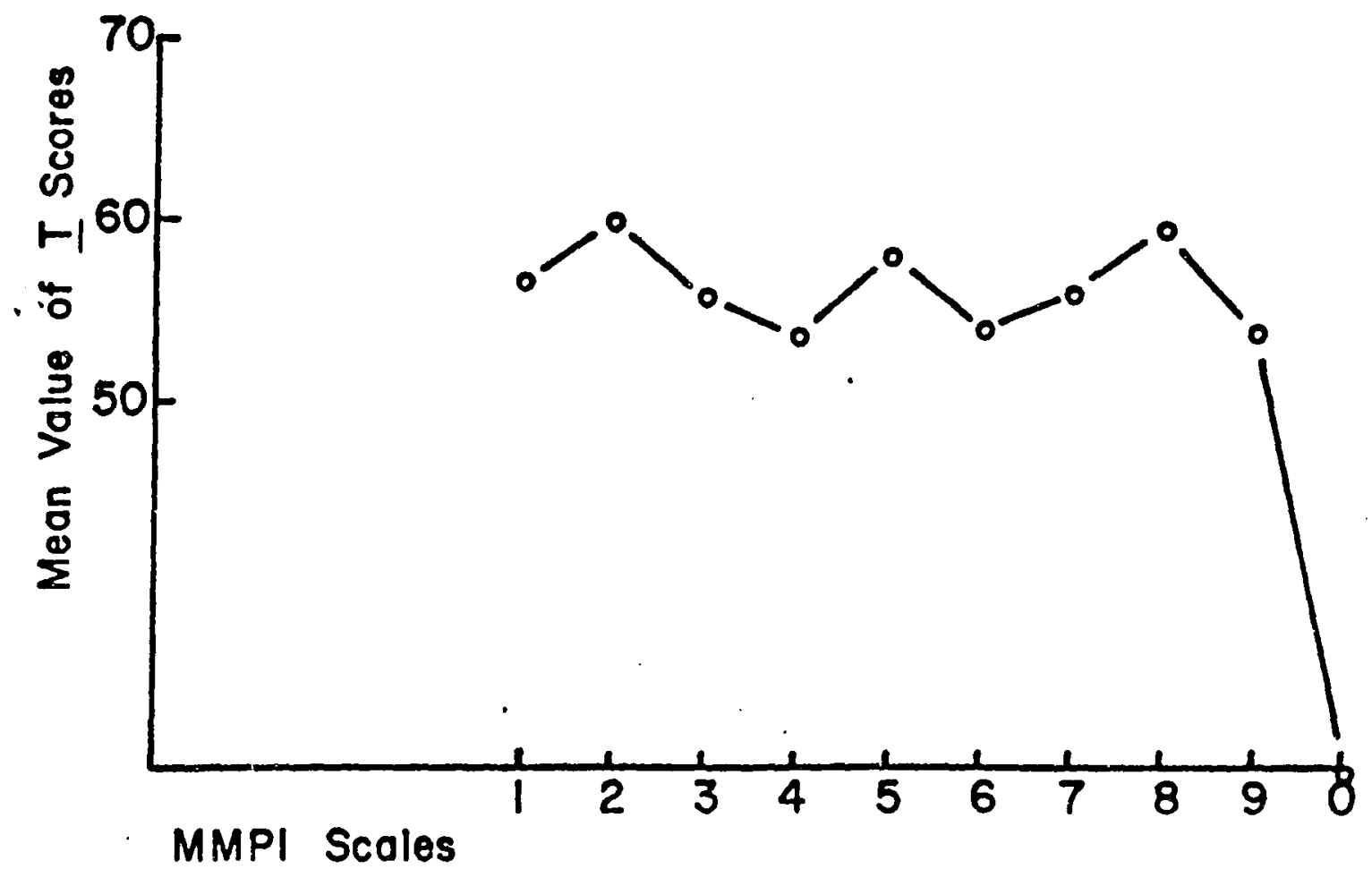

Figure 6. Mean values of MMPI T scores for hard-of-hearing patients (Myklebust, 1960). 
TABLE VI

THE PERCENT OF I SCORES ABOVE 70 ON OHE OR MORE SCALES OF THE MMPI

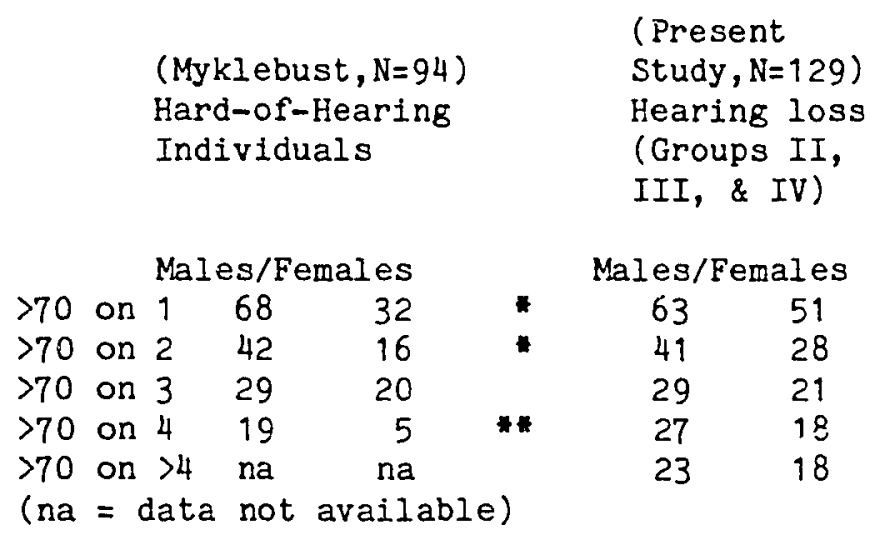

* Significant $\underline{z}$ scores between females

* Significant differences for both males and females

The combined groups, ald the patients in the study.

After examining each of the group results individual-y the data were then subjected to discriminant analysis in an effort to confirm whether between-group differences could be detected. The discriminant analysis indicated that there were several differences between groups and these are shown as Univariate $E$ ratios. Significance in terms of these $E$ ratios, with three and 142 degrees of freedom, was found for the following variables: Age, $E, K$, and Sc (Table VII). 
TABLE VII

$$
\begin{gathered}
\text { UNIVARIATE E RATIOS } \\
\text { VARIABLES REACHING SIGNIFICANCE } \\
(p<. \overline{0} 5)
\end{gathered}
$$

\begin{tabular}{crc} 
Variable & E & \multicolumn{2}{c}{ Significance } \\
Age & 10.41 & 0.0000 \\
E & 2.85 & 0.0398 \\
K & 3.63 & 0.0145 \\
Sc & 2.84 & 0.0403
\end{tabular}

In an attempt further to differentiate between the variables which may be responsible for the significant findings, a special statistical test entitled "Oneway" was utilized to allow comparisons to be made between the groups based on the questions that were raised at the beginning of the study. These comparisons are reported in Table VIII. Contrast 1, comparing the two tinnitus-primary groups revealed differences on scales $L, K$, and Pa. It appeared that the normal hearing patients made a greater attempt to present themselves in a favorable light than were the patients who had a hearing loss associated with tinnitus. Contrast 2, which made comparisons between the hearing-loss groups combined with tinnitus groups, revealed differences on scales $E$ and Hs. These differences suggest that the patient with tinnitus as the primary problem is more concerned with that complaint and is issuing a greater "cry for belp" than the patient for whom the hearing loss is perceived as the greater problem. 
TABLE VIII

STUDENT'S $\mathrm{t}$ PROBABILITIES FOR THE DIFFERENCES BETWEEN MEANS OF THE FOUR GROUPS AND COMBINATIONS OF THE GROUPS FOR EACH OF THE 13 MMPI SCALES

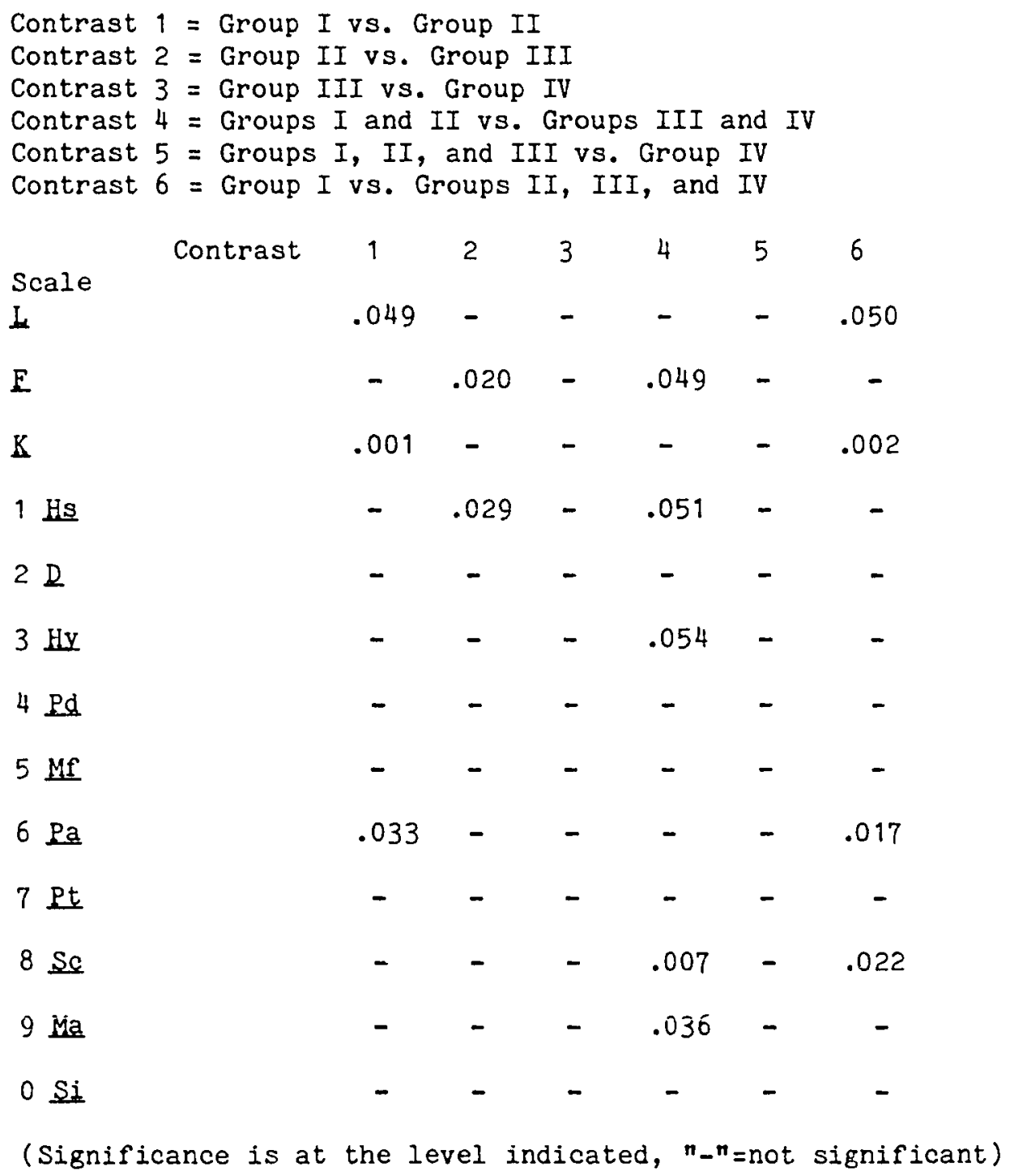


Contrast 3 provided no significant differences between the hearing-loss-primary groups. Contrast 4 provided information when the tinnitus-primary groups were compared with the hearing-loss-primary groups. This contrast yielded five scales with significant differences: $E$, Hs, Hy, Sc, and Ma. The first three of these scales represent a greater indily concern and attempt to get help for their problem on the part of the timitus-primary patients. The differences on the last two scales may be age related (the hearing-loss-primary groups had a higher mean age than the tinnitus-primary groups; 60.3 years vs. 47.1 years). It may also indicate that the tinnitus-primary groups are more troubled by their problem than the hearing-loss-primary groups. Contrast 5 , which compared the tinnitus groups with the non-tinnitus group, yielded no significant differences. Contrast 6 , where the normal-hearing, tinnitus only group was compared with the hearing-loss groups, revealed significant differences on four scales, $L, K, \mathbf{P a}$, and $\mathbf{S c}$. These differences suggest that the normal-hearing, tinnitus only group had a much greater defensive attitude toward taking the test and was much more concerned with making a favorable appearance. Members of this group may have a greater tendency to place blame on others for the problems they are having as a result of tinnitus and may also have difficulty with social relationships. These last differences on scales $\sigma$ and 8 may aiso be age-related.

Another way of looking at these particular relationships is to compare the percentages of all of the patients in this study who scored above 70 on each of the MMPI scales (See Table IX). 
The test for significance of the difference between two proportions (z-scores) revealed that the groups with tinnitus as the primary complaint generally had more of these "poorly adjusted" scores than those groups who had a primary complaint of hearing loss.

TABLE IX

PERCENT OF PATIENTS IN EACH GROUP WHO HAD ELEVATED SCORES ON THE MMPI SCALES

\begin{tabular}{|c|c|c|c|c|c|c|c|}
\hline Scales & Group I & & Group II & & Group III & & Group \\
\hline $\mathrm{L}$ & 12 & 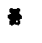 & 2 & & 2 & 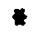 & 7 \\
\hline F & 29 & $\$$ & 13 & & 9 & & 7 \\
\hline $\mathrm{K}$ & 6 & * & 0 & & 2 & & 0 \\
\hline 1 & 35 & * & 23 & 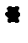 & 14 & $\star$ & 7 \\
\hline 2 & 29 & * & 36 & * & 18 & * & 27 \\
\hline 3 & 35 & & 30 & • & 23 & & 20 \\
\hline 4 & 24 & & 19 & * & 5 & * & 13 \\
\hline 5 & 18 & * & 10 & & 7 & $\star$ & 20 \\
\hline 6 & 29 & " & 16 & \# & 9 & 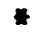 & 0 \\
\hline 7 & 24 & & 20 & & 16 & & 20 \\
\hline 8 & 53 & - & 39 & * & 32 & * & 13 \\
\hline 9 & 24 & * & 7 & & 7 & & 7 \\
\hline 0 & 18 & & 14 & & 14 & $\star$ & 7 \\
\hline
\end{tabular}

Overall percent of patients tho had at least one elevated score

$82 q \quad 63 \% \quad 57 \% \quad 60 \%$

* Significant zz scores between adjacent groups 
It was evident that, as a whole, the patients in this study had higher mean scores on the MMPI than the standard score of 50 (see Figure 1). Furthermore, when the present resuits are compared to a large population $(50,000)$ of medical patients (Swenson et al., 1973), the $t$ tests indicated differences on 9 of the MMPI scales. The $t$ test results are shown in Table $X$. While this is not a group with hearing problems, 1t is a group of socially functional people who are seeking help for a physical problem. The groups were well matched in age (see Table XI), and it was thought that a comparison would be reasonable. It can be seen from the profile of this medical group, Figure 7 , that there is none of the anxiety elevation on Scale 8 that is evident in the groups with hearing problems. There is, however, an expected elevation on Scales 1,2 , and 3 that would indicate a concern for bodily problems. Certain of the scales also exhibited significant Chi-Square levels when the variances were tested against the normal or theoretical variance indicating that the within-group variances were greater than would be expected of a normal population. These scores may indicate that there are different types of patients to be found along the dimension of many of the MMPI scales. Clinical observations reveal that most patients with tinnitus are socially well-adjusted but that some have significant psychological problems. 
TABLE X

t-STATISITC BETHEEN 50,000 MEDICAL PATIENTS AND

146 PATIENTS IN THIS STUDY(Swenson et al.,1973).

Scale $t$ Significance at level indicated

or ns for not significant.

L $\quad-1.9$ ns

E $\quad-6.9 \quad .001$

$\begin{array}{lll}\mathrm{K} & 5.0 \quad .001\end{array}$

Hs $\quad 1.9$ ns

D $\quad-2.6 \quad .02$

Hy $\quad-1.1 \quad$ ns

러 $\quad-2.9 \quad .01$

Mf $\quad-3.3 \quad .001$

Pa $\quad-4.0 \quad .001$

Pt $\quad-0.9 \quad$ ns

Sc $\quad-7.1 \quad .001$

Ma $\quad-2.3 \quad .05$

S1 $\quad-4.8 \quad .001$ 
TABLE XI

A COMPARISON OF AGE RANGE OF PATIENTS IN THIS STUDY WITH THE MEDICAL POPULATION IN THE MMPI SOURCE BOOK (Swenson et al, 1973)

$\begin{array}{ccc}\text { Age Range } & \text { Medical Patients } & \text { Tinnitus Study Patients } \\ <20 & 2 \% & 1 \% \\ <30 & 5 \% & 5 \% \\ <40 & 12 \% & 14 \% \\ <50 & 22 \% & 19 \% \\ <60 & 29 \% & 21 \% \\ <70 & 22 \% & 29 \% \\ 70+ & 7 \% & 10 \%\end{array}$

An interesting similarity of the profiles of groups II, III, and IV to profiles of patients with aphasia, epilepsy, and brain lesions can be seen by examining Figure 8 . Some theorists have speculated that tinnitus may be of central nervous system origin and when similarities with CNS abnormalities such as these are found, such findings tend to support those theories. A need may therefore be indicated for further research in this area. 


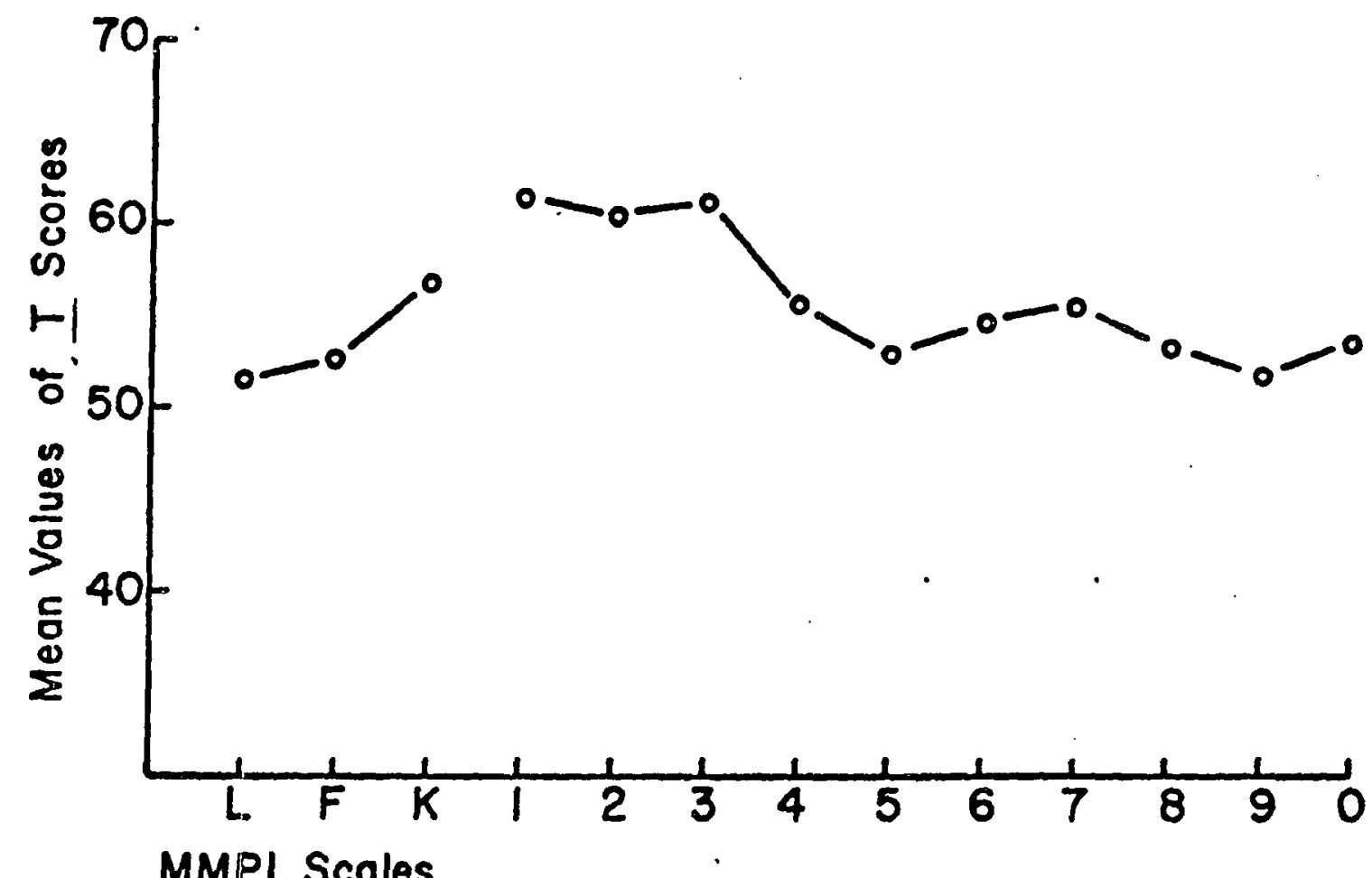

Figure 7. Mean values of MMPI T scores for medical population of the University of Minnesota (Swenson et al., 1973). 


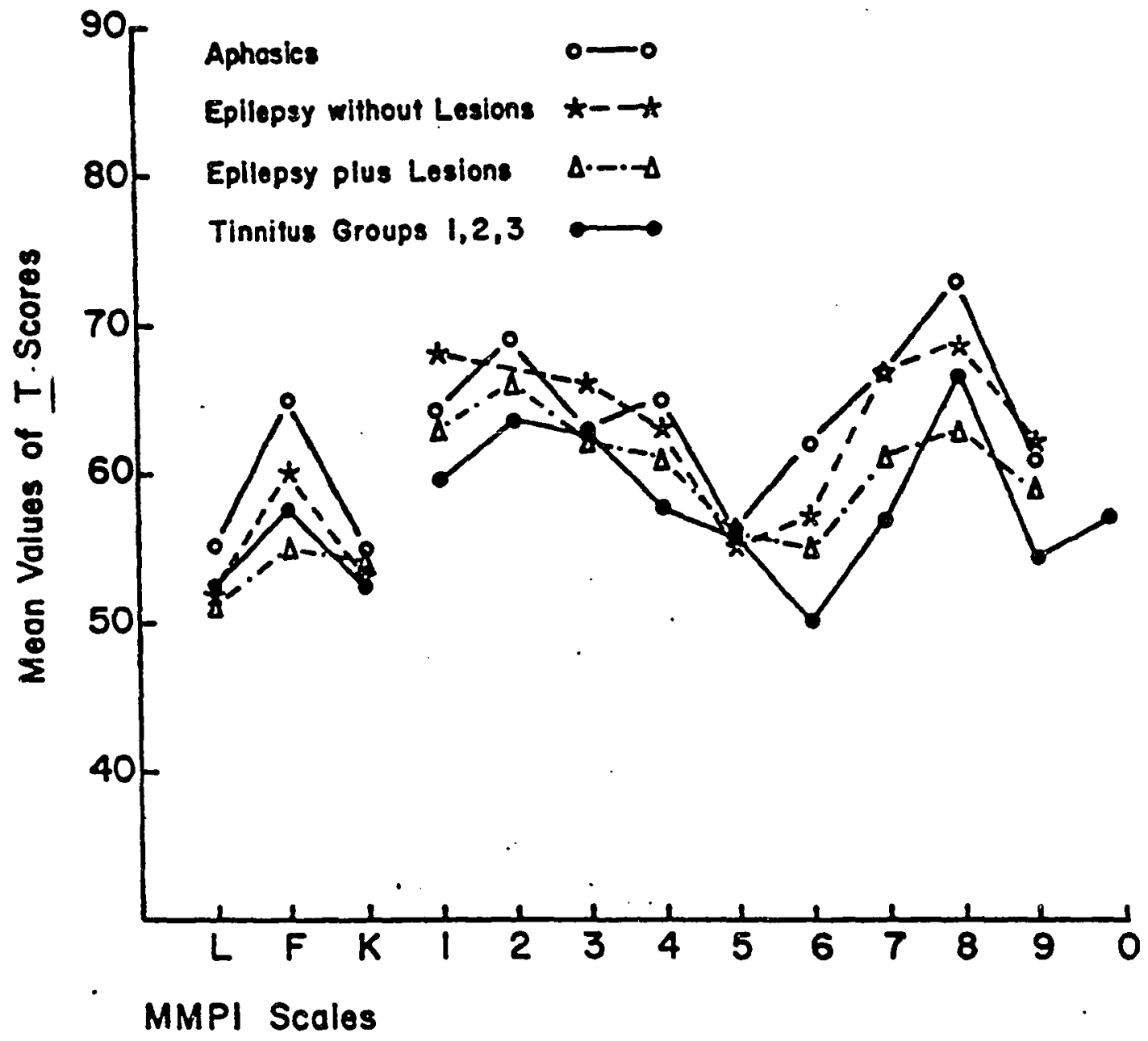

Figure 8. Mean values of MMPI T scores for patients with Aphasia or Epilepsy or Tinnitus 
It was hoped that discriminant analysis would reveal some combination of variables by which the groups could be defined. Sometimes, when groups are compared on the basis of one variable at a time there isn't sufficient power to discern subtle differences. On the other hand, sometimes the differences found in these comparisons cannot be enhanced by subjecting them to the more complicated analysis. At each step of the discriminant analysis, Group I was found to be different from the other three groups. At step 3 where variables $E, K$, and $\mathrm{Hy}$ were included, Group I maintained that difference, but Group II was also shown to be different from Group III. At this step the analysis accounted for about $15 \%$ of the variance among the groups. Step 4, which included variables $L, E, K$ and $H y$, also shows Group $I$ to be distinct but Group II has lost its distinction. Finally at step 5 only Group I remains different from the other groups. A short summary of the discriminant results is found in Table XII.

On the basis of the above findings, answers to the research questions posed earlier can be addressed.

Question 1. Are there significant differences between the scores on the various gcales of the MMPI for Croup I and Group II versus Group III and Group IV?

The reader $k^{\prime l l}$ recall that in Groups I and I the primary complaint was tinnitus, and in Groups III and IV the primary concern was a hearing loss. 
TABLE XII

SUMMARY OF SPSS DISCRIMINANT ANALYSIS RESULTS

(Significances for steps $1-5$

between pairs of groups)

(Variables are cumulative, at step 5, 5 are present.)

$\begin{array}{ccc}\text { Group } & \text { (Step and } \\ \text { variable) } & \text { I } \\ \text { II } & \text { (1) K } & .001 \\ & \text { (2) E } & .001 \\ & \text { (3) Hy } & .002 \\ & \text { (4) L } & .002 \\ & \text { (5) Sc } & .001\end{array}$

III (1) K $\quad .013$

$\begin{array}{lll}\text { (2) } \mathrm{E} & .0003 \quad .065\end{array}$

(3) $\mathrm{Hy} \quad .001 \quad .045$

$\begin{array}{lll}\text { (4) } \mathrm{L} & .0007 & .082\end{array}$

(5) Sc $\quad .0006$

IV $\quad(1) \mathrm{K} \quad .016$

(2) $\mathrm{E} \quad .015$

(3) Hy $\quad .035$

(4) $\mathrm{L} \quad .058$

(5) $\mathrm{Sc} \quad .021$ 
It is interesting to observe the differences which exist if the four groups are combined into two categories dealing primarily with tinnitus versus hearing loss. Table XIII indicates the number and percent of patients in each group who had two or more scores of 70 or greater on the MMPI. It is immediately apparent that there is a marked difference between Groups I and II and Groups III and IV. These results were further verified through the use of the "Onewayn analysis reported earlier. Even a cursory inspection of the results in Figure 1 shows a difference between the two categories. For the groups whose primary concern is tinnitus, the elevation in scores is primarily limited to the psychotic scales, whereas for those patients whose major problem is hearing loss, the elevation tends to be primarily in those scales related to neurotic symptoms. On the basis of these findings it is reasonable to conclude that there is a difference between the two categorical groups.

TABLE XIII

THE NUMBER AND PERCENT OF PATIENTS HAVING TWO OR MORE I SCORES ABOVE 70 ON THE MMPI

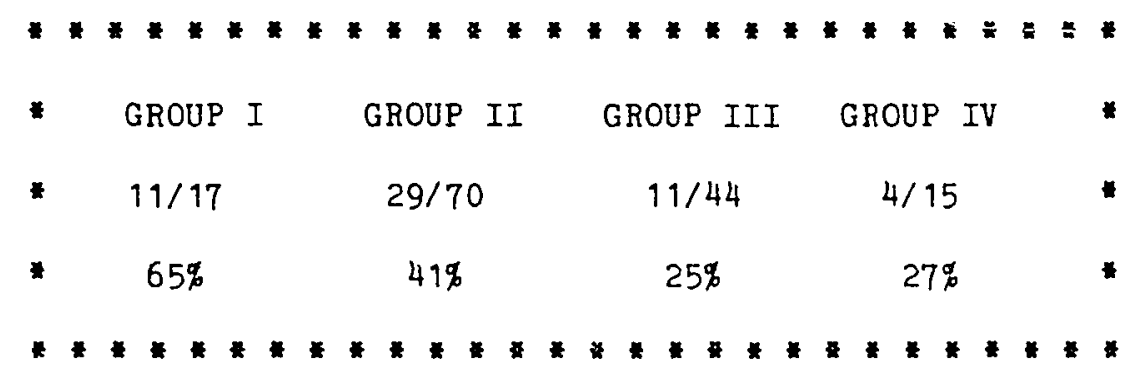


Question 2, Are there significant differences between the scores on the different scales of the MMPI for Group II and for Group III?

Recall that Groups II and III include patients who had both a hearing loss and tinnitus. The major difference between these two groups was that for Group II the primary complaint was tinnitus and for Group III it was the hearing loss. The resultant profiles for these two groups in Figure 1 show patterns that are similar in shape but slightly elevated for Group II. When these differences are subjected to an analysis of variance, the only significant differences between the two groups occurred for scale $E$ and scale 1 . These findings are not surprising in that both scales reveal a situation whereby the patient is likely to overstate his somatic concerns in order to obtain help. Although significant differences were determined for only two scales, it is important to point out that when there are one or more elevated scores, six scales differentiated these groups. Discriminant analysis showed significant differences in percentage between these groups when the variables $K, E$, and $H y$ were included in the analysis. Furthermore, Table XIII also reveals a significant difference between the two groups. Therefore, on the basis of these findings, it appears that patients whose primary concern is tinnitus have more difficulty coping with their probiems than do those whose primary focus is hearing loss.

Questien 3. Is it possible to select scales that will differentiate between these four groups? 
The most logical conclusion one can make regarding this question is that no definitive statement can be made concerning the differences among the four groups. Discriminant analysis revealed that Group I was significantly different from the other groups at all steps of the analysis but that only a transitory separation was indicated between Groups II and III and none at all between Groups III and IV or Groups II and IV. This same picture is visible by inspection of Figure 1 where the profiles of Groups II, III, and IV lie close together and the Group I profile can be seen to be separated from them. When group membership is based on a second symptom and on a subjective evaluation of its importance to the patient, then results are not well-defined. Thus it appears possible to differentiate between tinnitus patients and hearing loss patients on the basis of the MMPI scales but no conclusions can be made regarding the choice of specific scales other than to suggest that some combination of scales might be employed to show differences among the four groups.

Question 4. Are there general statements that can be made about the tinnitus clinic population?

On the basis of the data obtained from this study it can be stated, with relative confidence, that the tinnitus clinic population represents a more disturbed group than one would expect in the general population. Mean scores from these patients on the MMPI scales were significantly different from normative groups and from medical patients with other than hearing disorders. The entire group provided scores that were different from a hard-of-hearing population as well (Figures 1 and 8 ). 
Tinnitus seems to be accounting for these differences and, in fact, appears to be associated with coping problems for a large number of these patients. Thirty-eight percent of the sample displayed significantly malajusted personalities on the basis of two or more elevated MMPI scale scores. More men than women are seen at the tinnitus clinic. This might be accounted for by the greater incidence of noise trauma hearing damage for men but it might also be influenced by the fact that men appear to be more disturbed by tinnitus and hearing problems than women. 
CHAPTER V

SUMMARY AND CONCLUSIONS

The phenomenon referred to as tinnitus has been known and referred to as long as history has been written. The resurgence of interest in this problem has taken place during the last ten years chiefly because of the work done by Dr. Jack Vernon, Director of the Kresge Hearing Research Laboratory, Portland, Oregon. The incidence of the problem is great, perhaps as many as $20 \%$ of the population report having tinnitus. It is suspected that almost everyone can hear some internal noises in an extremely quiet situation. For some people tinnitus is a distressing situation, but it is not known whether the tinnitus causes the stress or the stress causes the tinnitus. Present research is concerned with identifying the causes of tinnitus, the location and identification of the physiological correlates that contribute to the problem, the possible effectiveness of certain drugs to relieve tinnitus, and the efficacy of masking and biofeedback on tinnitus.

Treatments for tinnitus had been largely ineffective until Dr. Vernon developed the technique called masking, that is, substituting an external sound for the internal noise. Not all patients respond to any one treatment yet devised and finding some way to relieve the incessant noise, even partially, is a task that consumes the lives of many of the tinnitus sufferers. 
Tinnitus, although physiological in nature, ofter results in a personality change. The purpose of the present study is to investigate the various changes in personality that occur for the four different groups of patients. This investigation was guided by the hypothesis that patients who had tinnitus and the tinnitus was considered by them to be a problem, would be different from those for whom tinnitus was not a problem. The present study was designed in an effort to test this hypothesis and attempt to measure the amount of distress that the tinnitus was causing. Patients were asked to complete a questionnaire and to answer the questions posed on a short form of the MMPI. The information that was obtained from the MMPI was then analyzed and the questions posed by the study were answered.

The results of the study were discussed separately for each of the four groups. Group I, tinnitus only; Group II, tinnitus-primary, with hearing loss; Group III, hearing-loss-primary, with tinnitus; and Group IV, hearing loss only. The scores obtained on the MMPI scales were analyzed by using computerized techniques available in the SPSS package. Elevations were observed for each of the groups on several of the scales. Individual patient scores were examined and the magnitude of these scores provided a measure of how great a problem existed. Comparisons were made between and among groups and with other populations.

On the basis of the results it seemed reasonable to conclude that sufficient evidence was presented to indicate clearly that there is a problem in social adjustment for many tinnitus patients. 
However, it was considerably less clear how it might be possible to identify those tinnitus patients who are experiencing problems. It cannot be said that tinnitus causes abnormally high scores on the MMPI, but people who view tinnitus as a significant problem are more likely to have high scores than those who do not. Special subscales of the MMPI have been devised for patients with chronic problems such as low back pain. Certain subscales of the MMPI are often used by clinicians to identify certain areas of concern about a patient. These scales were examined in an effort to further identify the problems that seemed to be troubling patients. It was found that the items that were frequently endorsed by patients and caused the high scores on scales $8,6,3$, and 2, fell into four subscales. These were SclA, Sc3, PaZ and Hy2. (Graham, 1977) Information obtained from these subscales provides personality descriptions similar to those obtained in the earlier interpretation. However, this closer inspection of the items themselves indicated that tinnitus patients, in responding appropriately for their physical condition, may be artificially elevating their scores on the MMPI. Certain social alienation items can be interpreted as reasonable responses from these patients. A patient with a disorder such as tinnitus, with highly subjective symptoms, and who usually appears to be quite the same as everyone else, of ten has problems with family members and friends. The tinnitus patient who tries to make his or her family understand the nature of the problem often is portrayed as a complainer. 
If, on the other hand, he or she says nothing about it, then he or she is taken to be withdrawn or antisocial. Typical patients will not be seen to endorse items that indicate a feeling of getting a raw deal from life, but they will endorse items that indicate some family and group alienation. An item such as number 52 on the MMPI, "I prefer to pass by school friends, or people I know but have not seen for a long time, unless they speak to me first" (Hathaway \& McKinley, 1966), is one in which the positive endorsement will contribute to the elevation of the Scale 8 score. Tinnitus does not seem to interfere measurably with hearing perception, but of ten the patient thinks that it does and will say that he or she could hear quite well if only that infernal sound was not present. Another subscale Sc3, entitled "Bizarie Sensory Experiences," characterizes ringing or buzzing in the ears as one of the indicators of a person who scores highly on this scale (Graham, 1977). When information such as this is applied to the tinnitus patient, one can obtain a false picture of that person. Subsales Hy2 and Pa 3 identify persons who are naive and optimistic about other people and who also have a need for affection and reinforcement (Greene, 1980).

\section{Conclusions}

From the above results the following conclusions appear reasonable.

1. The physiological problem of tinnitus is often compounded by associated stress.

2. The scores a patient obtains on the MMPI are affected by whether he or she has tinnitus alone or tinnitus combined with a hearing loss. 
3. For some tinnitus patients there appear to be problems of social adjustment that may be related to the tinnitus.

4. The MMPI can be used as an instrument to differentiate between the tinnitus versus the hearing-loss patient.

5. When compared to patients who have medical problems not associated with hearing or tinnitus, the MMPI scale scores were significantly elevated.

Based on the results of this study the hypothesis, which states that tinnitus patients, or patients with both tinnitus and hearing loss, where the tinnitus is perceived as the greater problem, would have personality characteristics that differentiate them from patients with hearing loss alone, or with both hearing loss and tinnitus where the hearing loss is perceived to be the greater problem, can be accepted. 


\section{REFERENCES}

Ambrosino, S. V. Neuropsychiatric aspects of tinnitus. In A. Shulman (Ed.), Tinnitus: Proceedings of the first international tinnitus seminar (New York 8-9 June 1979). Journal of Laryngelegy and Otolegy, Supplement 4, 1981.

Anastasi, A. Rsychelosical testing. New York: MacMillan Publishing Company, 1976.

Baron, S. H. Experiences with parenteral vitamin A therapy in deafness and tinnitus. Laryngescope, 1951, 61, 530-547.

Brummett, R. E. Drug treatment for tinnitus? Phacmindex, 1981, $23,9-16$.

Bruning, J. L., \& Kintz, B. L. Computational Handbook of Statistics. Glenview, Illinols: Scott, Foresman and Company, 1977.

Canter, A. H. MMPI profiles in multiple sclerosis. In G. S. Welsh \& W. G. Dahlstrom (Eds.), Basic readings on the MMPI in Dsycholesy and medicine. Minneapolis: University of Minnesota Press, 1956.

Dahlstrom, W., Welsh, G., \& Dahlstrom, L. An MRIPI Handbeok, (Vel II,) Research Applicationse Minneapolis: University of Minnesota Press, 1975.

Donaldson, I. Tinnitus: A theoretical view and a therapeutic study using amylobarbitone. Jeurnal of Laryngelegy and otology, 1978, 22, 123-130.

Drucker, T. Drugs that can cause tinnitus. American Tinnitus Association Newsletter, 1979, 4. 3-5.

Emmett J., \& Shea J. The treatment of tinnitus with tocainide HCl. Unpublished manuscript available from the Shea Clinic, Memphis, Tennessee, 1980.

Evered, D., \& Lawrenson, G. (Eds.) Iinnitus-Ciba foundation Sympesium:85. London: Pitman Books, 1981.

Fowler, E. P., \& Fowler, E. P., Jr. Somatopsychic and psychosomatic factors in tinnitus, deafness and vertigo. Annals of Otolegy Rhinolegy and Laryngolegy. 1955, 64, 29-37.

Frankenhaeuser, M. \& Patkai, P. Catecholamine excretion \& performance under stress. Perceptual and Motor Skilis, 1964, 19, 13-14. 
Gardner, R. Coping with tinnitus. American Tinnitus Association Newsletter, 1982, I, 4-5.

Gildston, H. \& Gildston, P. Personality changes associated with surgically corrected hypoacusis. Audiolegy, 1972, 11, 354-367.

Good, P. K-E., \& Brantner, J. P. A practical guide te the MMPI. Minneapolis: University of Minnesota Press, 1974.

Goodey, R. J., Drugs in the treatment of tinnitus. In D. Evered \& G. Lawrenson (Eds.) Tinnitus, Ciba foundation symposium 85. London: Pitman, 1981

Goodhill, V. The management of tinnitus. Lacyngescope, 1950, 60, $442-450$.

Goodhill, V. Pathology, diagnosis and therapy of deafness. In L. E. Travis, (Ed.), Handbook of Speech Patholegy, New York: Appleton-Century Crofts, Inc., 1957.

Goodwin, P. E., \& Johnson, R. M., The loudness of tinnitus. Acta etolaryngelesica, 1980, 20, 353-359.

Graham, J. M. Tinnttus in children with hearing loss. In D. Evered \& G. Lawrenson (Eds.), Tinnitus (Cjba Foundation Sympesium 85). London: Pitman Medical, 1981.

Graham, J. R. The MAPI, a practical guide. New York: Oxford University Press, 1977.

Graham, J. T. An analysis of certain psycholosical parameters of tinnitus aurium. Unpublished doctoral dissertation, Stanford University, 1960.

Green, R. E., \& Douglass, C. C. Intracranial division of the eighth nerve for Meniere's disease: a followup study of patients operated on by Dr. Walter E. Dandy. Annals of Otolegy Rhinelegy and Lacyngelegy, 1951, 60, 610-621.

Greene, R. L. The MMPI an interoretive manual. New York:Grune \& Stratton, 1980 .

Gynter, M. D., \& Gynter, R. A. Personality inventories. In I. B. Weiner (Ed.), Clinical methods in Dsycholegy, New York: Wiley, 1976. 
Hanvik, L. J. MMPI Profiles in patients with low-back pain. In G. S. Welsh \& W. G. Dahlstrom (Eds.), Basic readings on the MMPI in Dsychology and medicine. Minneapolis: University of Minnesota Press, 1956.

Hathaway, S. R., \& McKinley, J. C. The Minnesota multiphasic Dersonality inventory. New York: The Psychological Corporation, 1966.

House, J. W., Miller, L. \& House, P.R., Severe tinnitus: treatment with biofeedback training (results in 41 cases). Iransactions of the Academy of Opthamelogy \& Otology, 1977, 84. 697-703.

House, P. R. Personality of the tinnitus patient. In D. Evered \& G. Lawrenson (Eds.) Iinnitus, Ciba foundation symposium 85. London: Pitman, 1981.

House, P. R. Personal communication, January, 1982.

Hovey, H. B. MMPI profiles and personality characteristics. In G. S. Welsh \& W. G. Dahlstrom (Eds.), Basic readings on the MMPI in Dsychology and mediclne. Minneapolis: University of Minnesota Press, 1956.

Israel, J., McTigue, S., Brown, J., Schleuning, A., \& Brummett, R. Treatment of tinnitus with lidocaine. In preparation, Oregon Health Sciences University, 1981.

Jackson, C. W., Jr., Ellis, R., Hughey, G. A., \& Schlotfeldt, R. M. Auditory deprivation: stapedectomy patients who reported social change due to hearing impairment versus those who did not. Proceedings, 79th Annual Convention, American Bsychological Association, 1971, 637-638.

Johnson, L. F. Surgery of the sympathetic in Meniere's disease, tinnitus aurium, and nerve deafness: a new concept in acute fulminating Meniere's di sease. Archives of Otology, 1954. 59, $492-498$.

Johnson, R. M., Personal communication, June, 1982 . 
Kennedy, A. Cochlear, neural \& subjective factors in tinnitus. Proceedings of the Royal Society of Medicine, 1973, 46.

Kunce, J. T. MMPI scores and adaptive behaviors. In C. S. Newmark (Ed.) MMPI clinical and research trends. New York: Praeger Scientific, 1979.

Lanyon, R. I. A handbook of MMPI group profiles. Minneapolis: Univ. of Minnesota Press, 1968.

Levine, E. S. The psychology of deafness. New York: Columbia Univ. Press, 1960.

Lewy, R. B. Treatment of tinnitus aurium by the intravenous use of local anesthetic agents. Archives of otolaryngology, $1937,25,178-183$.

Lieberman, M. A. Adaptive processes in late life. In N. Datan \& L. H. Ginsberg (Eds.), Lifespan developmental psychology: normative life crises. New York: Academic Press, 1975.

Melding P. S., Goodey, R. J., \& Thorne, P. R. The use of intravenous lignocaine in the diagnosis and treatment of tinnitus. Journal of Laryngelegy and Otology, 1978, 22, 115-121.

Myklebust, H. R. The psychology of deafness, New York: Grune and Stratton, 1960.

National Center for Health Statistics, Hearing status and ear examination-findings among adults, United States 1960-1962. Vital and health statistics, Washington, DC: U. S. Dept. Heal th Education and Welfare, Series 11, 32, 1968.

Newmark, C. S. A bibliography on abbreviated forms of the MPPI. In C. S. Newmark (Ed.) MMPI clinical and research trends, New York: Praeger Scientific, 1979.

Nie, N. H., Hull, C. H., Jenkins, J. G., Steinbrenner, K., \& Bent, D.H. Statistical Package for the Social Sciences, New York: MoGraw-Hill, 1975. 
Overall, J. E., \& Hunter, S. Factor structure of the MMPI-168 in a psychiatric population. Journal of Consulting and Clinical Psychology, 1973, 41, 284-286.

Overall, J. E., \& Klett, C. J. Applied Multivariate Analysis. New York: McGraw-Hill, 1972.

Pizzichetta, V. \& Ferraro G. A study of the influence of psychic factors in the pathogenesis and evolution of otosclerosis. Analysis of psychic personality profile by objectivation tests. Nueve Archives Italy, 1975, ORL 4(1), 99-104. (Abstract)

Pizzichetta, V. and Ferraro, G. The psychic personality in otoscierotic subjects. Annals otorhinolaryngology Ibero-American, 1978, $5(6), 619-625$. (Abstract)

Ramsdell, D. A. The psychology of the hard-of-hearing and the deafened adult. In H. Davis \& S. R. Silverman Hearing and Deafness, New York: Holt, Rinehart and Winston, 1960.

Reiter, D. Concepts of dental occlusion, American Journal of Otoiggy, $1980,1,245-255$.

Saltzman, M., \& Ersner, M. S. A hearing aid for the relief of tinnitus aurium. Laryngescope, $1947,57,358-366$.

Selye, H. Stress without distress. Philadelphia: J. B. Lippincott, 1974.

Shea, J. J., \& Harrell, M. Management of tinnitus aurium with lidocaine and carbamazepine. Laryngoscope, 1978, 88, 1477-1484.

Shulman, A. (Ed.) Tinnitus: Proceedings of the first international tinnitus seminar ( New York 8-9 June 1979). Journal of Laryngology and Otology, Supplement 4, 1981.

Stephens, S. D. G. Evaluating the problems of the hearing impaired. Audielegy, $1980,19,205-220$.

Swenson, W. M., Pearson, J. S., \& Osborne, D.An MMPI source book; Basic item, scale, and pattern data on 50, lol medical patients. Minneapolis: University of Minnesota Press, 1973.

Szasz, T. S. The myth of mental iliness. New York: Harper and Row, 1974 . 
Vernon, J. Attempts to relieve tinnnitus. Jounnal of the American Audielegical Seciety, $1977,2,124-131$.

Vernon, J. The other hearing problem produced by excessive noise exposure. National Safety Congress Transactions, 1977, 21, 21-24.

Vernon, J., Schleuning, A., Odell, L., \& Hughes, F. A tinnitus clinic. Ear. Nese \& Throat Journal, 1977, April.

Vernon, J., \& Schleuning, A. Tinnitus: a new management. Laryngescese, $1978,88,413-419$.

Vernon, J. \& Meikie, M. Tinnitus zasking:unresolved problems. In D. Evered \& G. Lawrenson (Eds.) Tinnitus, Ciba foundation symposium 85. London: Pitman, 1981.

Vernon, J. Personal communication, April, 1982

Weiner, D. N. Personality Characteristics of selected disability groups. In G. S. Welsh \& W. G. Dahlstrom (Eds) Basic readings en the MMPI in osychelegy and medicine, Minneapolis:

University of Minnesota Press, 1956.

Weinshel,E. M. Some psychiatric considerations in tinnitus. Hillside Hospital New York Journal, 1955, 生, 67-92.

Zimbardo, P. G. Deafness as a cause of paranoia in the elderly. Science, June $26,1981$. 
APPENDIX 


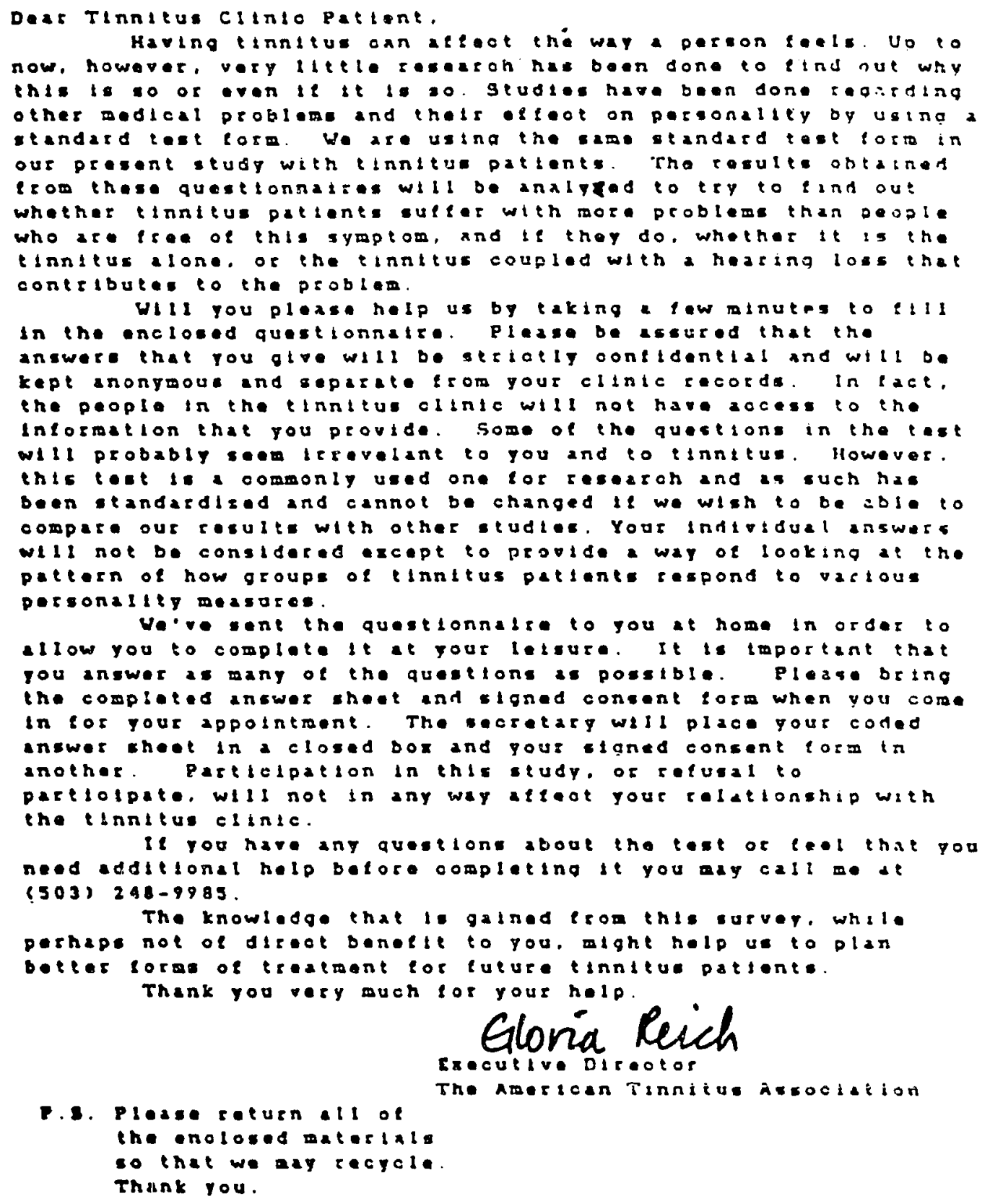




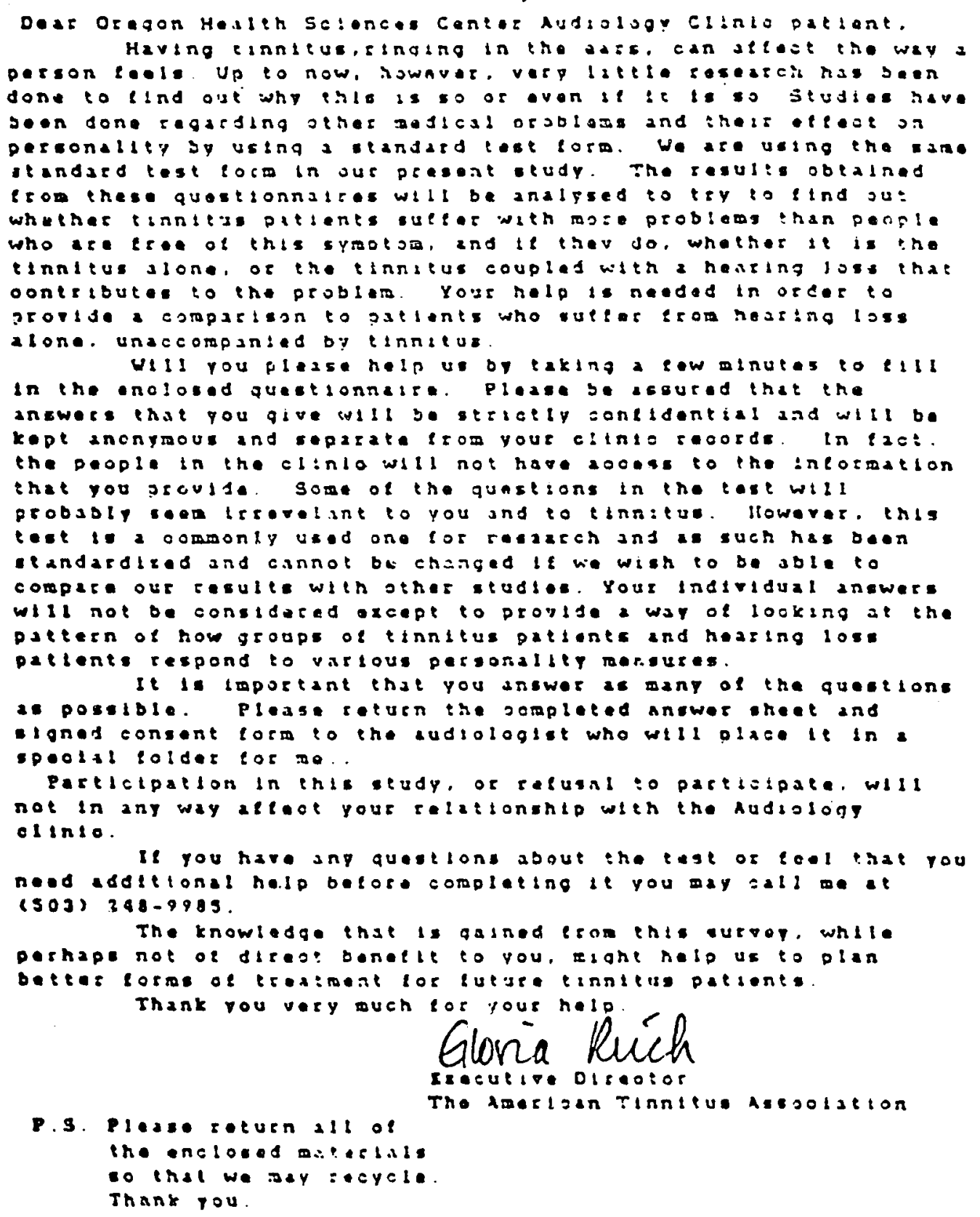




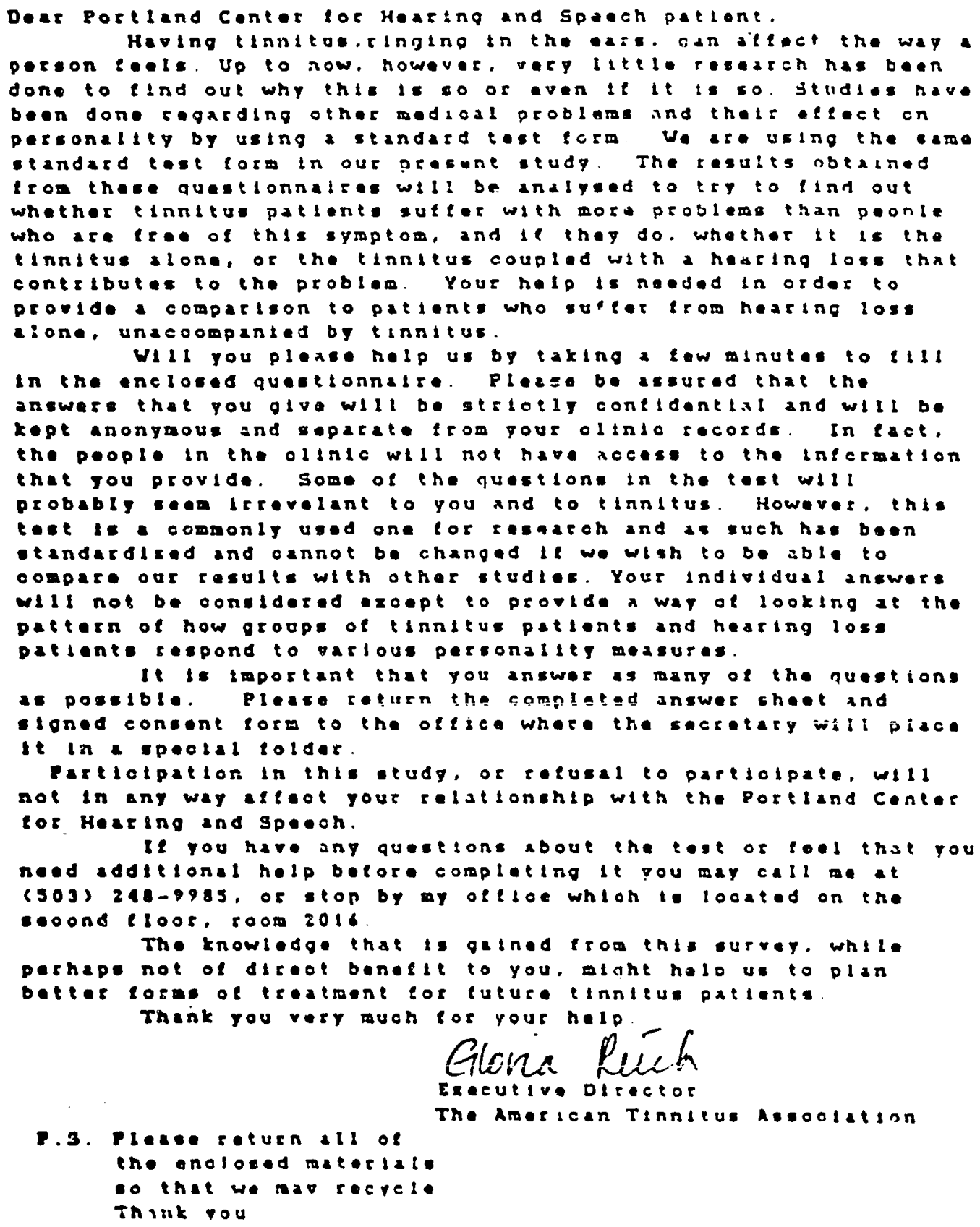




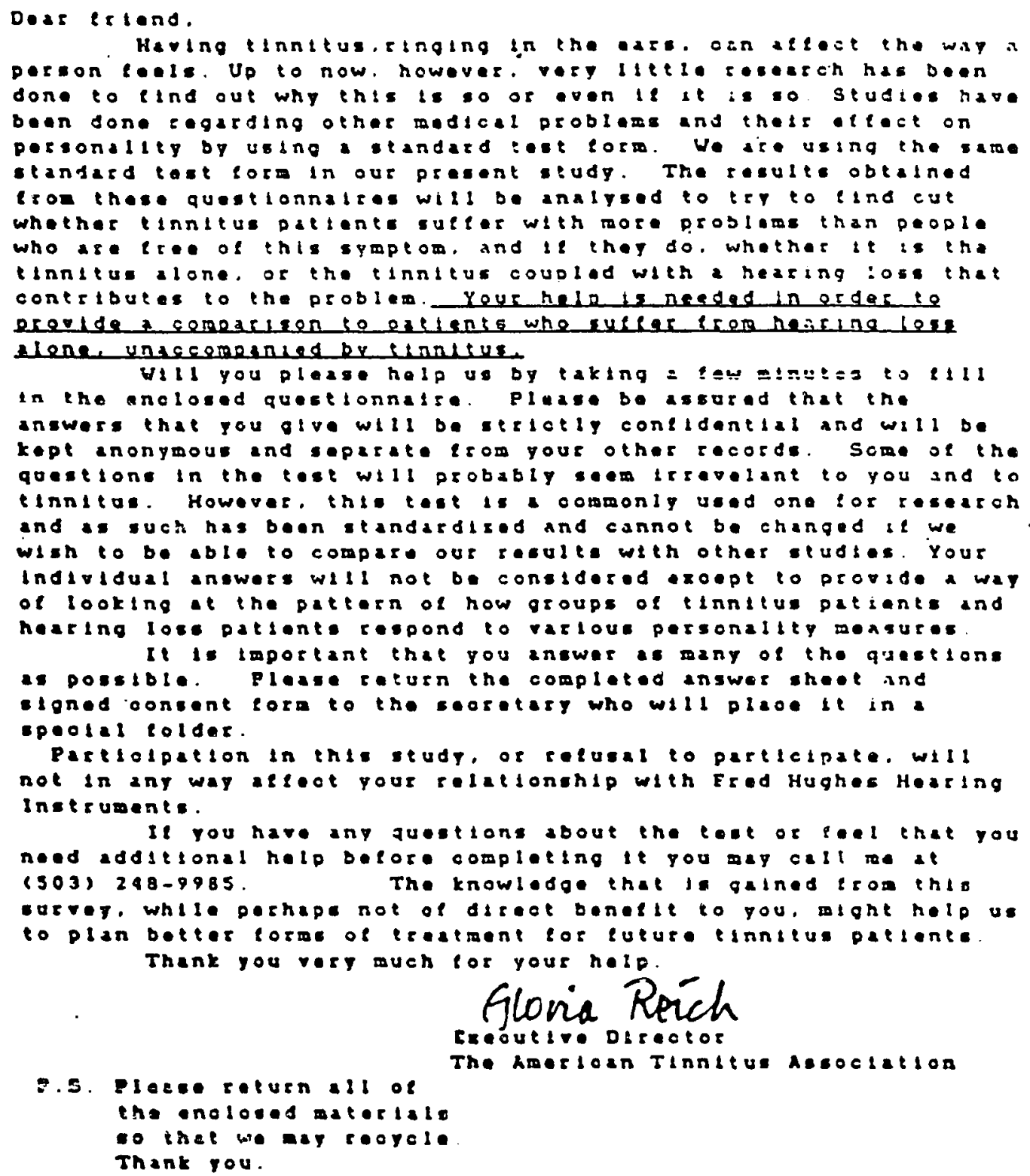


INDIVIDUAL DATA SHEET FOR PATIENT PERSONALITY SURVEY

DATE

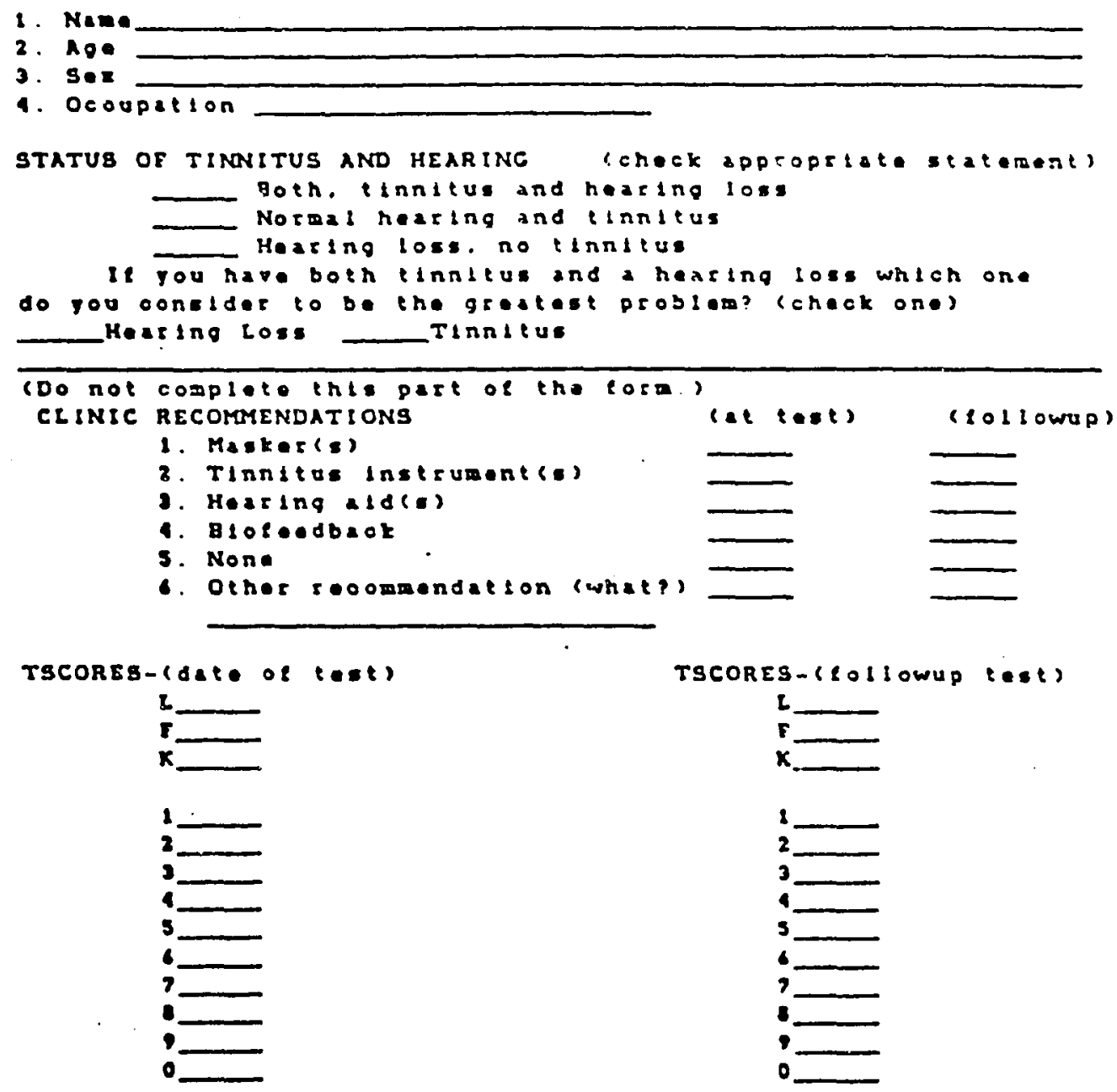

If posable, please artech a copy of your audlogran to thie sheet. Thank you. 
TINMITUS CLINIC QUESTIONMAIRE

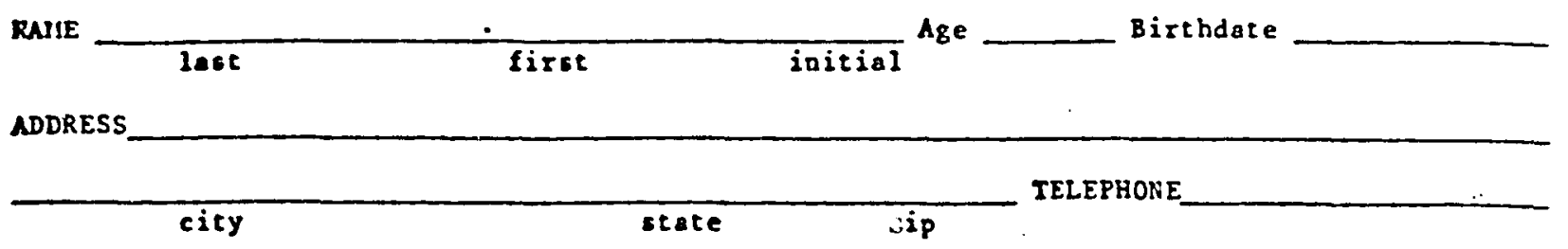

REFERRED TO TIHIITUS CIIHIC SY

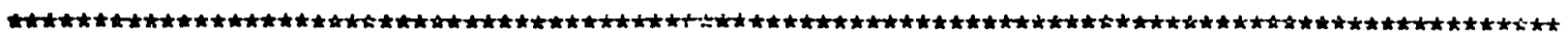

1. BOW LONG HAVE YOU BEEN ALARE OF TINNITOS (noise or sounds in your ears or head)?

2. Were illness, accident or other special circumstances associated with the onset of your tinnitus:

\section{(Please describe briefly)}

3. HHERE DOES YOUR TIIM:ITUS APPEAR TO BE LOCAIED?

WHERE IS IT WOSST? (If in more than one location)

4. Has the location of your tinnitus changed since it first began? [I No [I Yes:

\section{(explain)}

3. SINCE IT STARTED, RAS YOUR IINNITUS:

II Grown vorse II Remained about the same |I Improved

6. Does your tionitus chenge when you:

(1) Lie down or bend over

II Sit or stand up quickly

(1) Cough or sneeze
[1 Go up to higher alticude

(] Come dow from high altitude

(1) No, nothing I do seems to affect my Rinnitus

7. Is there saytbing you know of that changes your tinnitus in any way?
【】 Ho
1] Yes:

\section{(describe)}


IYPE OE SOUND HEARD

8. Is your tinnitus constantly there or do you hear it only part of the time?

I] Constanty there (1) Heard only part of time

If you hear your innitus only part of the time, describe briefly how auch of the time it

is there:

9. DOES YOUR TINNITUS USUALLY SOUND SIMTLAR TO ANY OF THE FOLLOWING? (Check all that apply to your (innitus):

\begin{tabular}{|c|c|c|c|}
\hline $\begin{array}{l}\text { Ringing } \\
\text { Clear tone } \\
\text { Hore than one tone } \\
\text { Whistle }\end{array}$ & $\begin{array}{l}\text { [) Bissing } \\
\text { [) Buzzing } \\
\text { [) Buw } \\
\text { [) Husic }\end{array}$ & $\begin{array}{l}\text { l] Sizzling } \\
\text { [) Transforoer noise } \\
\text { [) High tension wire } \\
\text { [] Crickets }\end{array}$ & $\begin{array}{l}\text { [] Puisating } \\
\text { [] Pounding } \\
\text { [] Ocean roar } \\
\text { [] Clicking }\end{array}$ \\
\hline
\end{tabular}

Il other:

(deceribe)

10. Has your tinnitus always sounded like that or bave you noticed changes in the type of sound heard?

I] The type of sound has stayed about the same

I) The type of sound has changed as follows:

11. About how long has your tinnitus sounded the way it does now?

IINNITUS STRENGTH OR LOUDNESS

12. How would you describe the strength or loudness of your USUAL tinnitus:

0 II Absent

1 [I Barely noticeable

2 [] Moderate

3 [] Very intense

4 [I Unconfortebly intense

13. Since it first started, has your tinnitus grown any louder or softer?

[1 No, no significant change (I Yes:

(Describe changes)

14. DOES THE LOUDNESS OF YOUR IINNITUS TEND TO FLUCTUATE (sodetimes louder, sometimes softer)?

$$
\text { I) No l] Yes }
$$

If YES, how OFIEN do changes occur:

MIEK do you usually notice changes

Dow LARCE are the changes usually:

(1) Barely noticeable

(I) Moderate

if Very warked

(1) Unpredictable 
TINNITUS SEVERITY

15. DOIS YOUR IINIITUS IKIERFERE WITI SLEEP? I] No I] Yes [] Sometimes

16. Has tinnitus interfered with your work? II No II Yes II Sometires

If YES, indicate whether tinnitus has caused eny of the following problems at vork: :

(1) Tinnitus rakes it uncomfortable to be in quiet

1) Tinnitus makes it difficult so concentrate

I] Tinnitus makes it harder to interact plessantly with others

(] Iinnitus aakes you irritable or nervous

[] Tinnitus makes you feel tired or ill

Il other tinnitus-related problems at work?

17. That is your work:

ถูos long have you been doing this type of vork:

18. During your time away frov vork, does your tinnitus interfere with any of the following activities:

\begin{tabular}{|c|c|c|c|c|c|}
\hline $\begin{array}{l}\text { Concentrating } \\
\text { Relaxing }\end{array}$ & $\begin{array}{l}\text { [] No } \\
\text { [] N:o }\end{array}$ & $\begin{array}{l}\text { 1) Yes } \\
\text { l] Yes }\end{array}$ & $\begin{array}{l}\text { Time with family } \\
\text { Iime with others }\end{array}$ & $\begin{array}{l}\text { [] No } \\
\text { [] No }\end{array}$ & $\begin{array}{l}\text { [) Yes } \\
\text { [] Yes }\end{array}$ \\
\hline Travelling & [j no & ij Yes & Other: & & \\
\hline
\end{tabular}

(j) soo, tinnitus does not interfere vith any of my activities

19. DOES THE SEVERITY OF YOUR IINHITUS TEND TO VARY FROH TIHE TO TIME? [I NO II YeS

If YES, how Erequent ly?

20. Have you found that any of the folloving make your tinnitus vorse:

Exposure to loud noise I] Sroking or other use of tobacco []

Use of alcohol. II Uce of marijuana []

Drinking caffeine-containing beverages (coffee, tea, cocos, cola-type drinks) |]

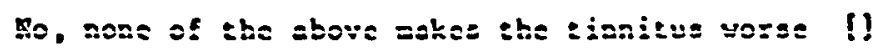

21. Does your tinnitus appear vorse when you:
Are tired
(]) No [] Yes
Are relaxed
II Ho II Yes
Are tense or aervous if Ho if Yes
Are in bed at night
I] No I] Yes

Any other time your tinnitus appess vorse? 
22. HOR HOULD YOU RATE THE SEVERITY OF YOUR IIHNITUS? (If the severity of your tinnitus varies, check the wost uSUAL level in the list below)

1 I] Tinnitus is there if attended to; usually ignored

2 II Tinnitus irritating but can sometibes be ignored; does not interfere seriously with work or social activities

3 Il Tinnitus difficult to ignore, but with effort can maintain work and other activities

4!I Tinnitus olways present and distressing; wakes it difficult to concentrate; can do only simple tasks

5 [I Tinnitus is overwhelming problen much or all of the time; unable to perform any work or social activities

Any other coments about the severity of your tinnitus:

ATTERTTS TO OBTAII RELIEF

23. Have you previously sought medical help for your tinnitus? (I No (I Yes:

(briefly indicate where and when)

24. Have you previously tried any of the following treatments for

tinnitus:

Biofeedback [] No l] Yes

If YES, did you obtain any relief:

Why did you stop the treatment:

Drug Therapy II Ho I] Yes

If YES, did you obtain any relief:

Why did you stop?

Mlasking I] No [] Yes

If YES, did you obtain any relief:

Why did you stop?

Hypnosis $\frac{\text { or }}{\text { Acupuncture If YES, did you obtain any relief: }}$

thy did you stop?

iny oinex forw of ireacuent if dio

If YES, did you obtain any relief:

Why did you stop?

25. Have you discovered anything which secos to help your rinaicus or sives some degree of relief?

G F


GISTORY OP GEARIYG AND EAR PROBLEKS

MASE

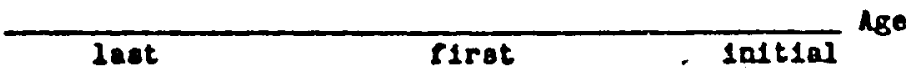

8e Blftideto

26. Heve you ever been dlegnosed as having any of the following:

[] Hondere's disease

Approx. Age

[] Ho

[1 Ios

[] Otosclerosis

[] Facial pain, numbees or paralyalo

[] Cholesteatoma

(] Labjrintbit1.

[] Mastolditis

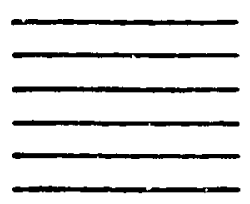

27. Do you have any otbor ear probleas or dnjury?

(] 10

[] Tes

If IES, please describe glving dates when possible:

28. Do jou ever experlance the followlag: (If IBS, ladicate how often and for how long)
D18zinese:
[] Ho [] Yoo:
Pala in the ear:
(1) Ho
[] Ies:
Fullness in the ear:
[] 1 .
[] Ies:

29. DO YOU YOTICB AMY BEARIHG DIFFICOLIIES?

[] no

[] Dot sure [] Ies

If IBS, what diffloult108 or problems are jou beving:

Mon did you begí to potice this typo of difficuley?

Une the onset of your hearlas problen sudded or eradual?

[) Oraduel (] sudden (date of onset, if known)

If It was auddon, was it asocclated vitb any of the following:
[] gunetre
[] rasoular problem
[] explos10n
[1. \$.1lnese
[] loud susto or
[1 other otber loud no180

[] unksown

(expla1n)

30. Dosa your bearlas cen to be gett1ng norse?

[1 10 [1 100

[】 Rot sure

31. Does your bearlag sees to Pluctuate? [] No

[] Tea: 
32. Hea your boarting obanged in ang otwor vay? [] to. [] Yos:

\section{(explaso)}

33. Is Jour bouring better in one sar or the otber? [] yo, botb oars tbe sare (]) Not aure [] Yos Is res, whlo's ear 10 your botter ear:

\section{[] RIOBT ear [] LEPT oar}

34. Do you flad loud sounde gore unpleasant than you used to? [] Bo [] Yoo If IRS, expla1a:

35. Do jou bave trouble undorstanding spoech?

[i Mo [1 Yes: When?

36. HAS AYYOHE RLSE IN YOOR FLHILI HAD PROBLEHS MITH TABIR BARS OR MEARIMO?

[1 Ho [] Yes---Thelr relationship to you:

What type of problea?

37. BATE YOD EYER YORW A HEARIHG ATD? [] HO [] YOS: (10dlante when for bor long)

Worn 10: [] LET ear [] RIGGr oar [] BOTH oars

Indicate make and model if possible:

How belprul was the hear1ag applificat1on?

Did the hoariag ald affeot your tinnitus in any way?

38. MAICE IS MORE OP 1 PROBLEM FOR YOD, IINGITOS OR REARIMG DIFEICOLTY?
[) Iinoitus
[l Bearias difficulty
ij niồ surs
[) They'ro oqually botbersomo

39. HATE TOU BEER EXPOSED TO LOUD SOONDS DORIMG ANY OF TBE FOLLONIMG:

[] Miltary sirvioe

[] Mork

[] Reoroational Letiritios

[] Otber:

for off10e use only 
MEDICAL AND HEALTH INFORMATION

MARE. BIRTHDATE

BIRTHPLACE EIS COLOR

ronth day yoar

40. HAVE YOU HAD ANY OF THE FOLLOUING:

[1 Ho

[] Tos (check all that apply):

\section{Noprex, age}

[] Arthrit1s or rhounatism

[] H1gh blood prossure

[] Heart disoeso

[] Blood disease

[] Blood ressel problea (phleb1t1s, var1cose reins, atherosclerosis, arter1osclarosis, oto.)

[] Luns diseaso or other respiciatory probleas

Other signifleant medicel problex: Ho [] Yes []
Aperox. Age

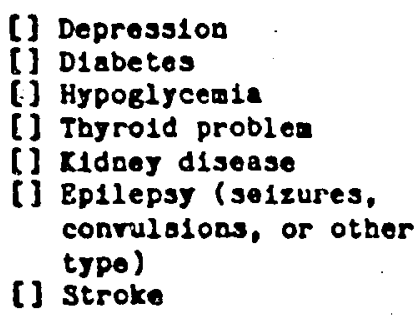

] seroke

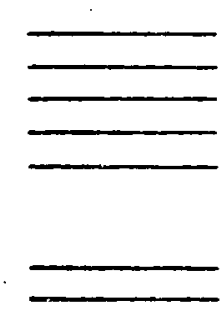

(desor 1be)

11. DO YOU HAVE FREQUEMT HEADACHES? [] HO [] YOS: HOW Of TOR?

42. ARB YOU CORREATLY IAKIMG ANY MEDICATIONS? [] HO [] YOS

If YES, please indioate the followiag:

Modication Hase

Amount. Prequency thon Began Tak1ng Taken

43. HAVE YOU HID AVI OP THE FOLLOIIHO:

[] Ho

[1 Ios (chock all that apply):

Apereke ise:

Aporer. age:

[1 Gorman measles (3-day neasles, rubella)

[] "Hard" measles

(] Humpo

(] Scarlet sever

(]) Whoopling cougb

(] Oiptheria

[] Rbousetic forer
[] Chicked por

(1) Herpes (any form)

[j Honoducleosis

(] Hepatitis

[] Tuberculosis

(1) Syphil1s

[j kalaria

Ozber comunicable diseases: 
44. HAVE YOU EVER had SIGNIFICANT hEAD OR HECR IMJURY:

If IES, old it lavolve:

[] Bion to boad

[] Loss of consclousness

[] Concussion

[] Mb1plash

[] Other (desoribe, give approxlente date)

45. HAVE YOU HAD SURGERY INYQLVIKG THE POLLONINO:

[] ilo

[] Yea

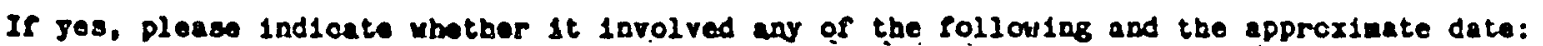

[1 Heart or blood resenla

[] Beck or aplanal cord

[1 Orel, rasial, iz jair

I] vithor olgniricant aurgery

46. DO YOU HAVE ANY RLEROIBST

[] He

[1. Ka4

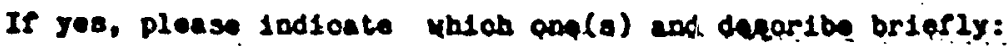

[] rood

[] Ininal

[] Other

47. DO YOD CUIRTITI HAVB AHY PROSLEKS WITH YOUR JERTH OR JAH?

If Yes, pleace obeck all that epply:

[1 Probleas chew10s

[] Jay pain

[] Otber:

[] Rollon

[] pruga soprex, date

48. DO YOU swore? (] No [] Iea:

$$
\text { (desertbe briefly) }
$$

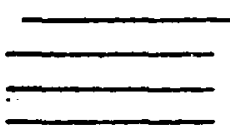

(how often/boy mach)

49. DO YOU DRINK LLCOHOLIC BETERLGES: [] No [I YPS; (how pftẹp/bow anch)

50. DO YOU DRINK CAPFEINE-CONTAIMIMO DEMERAORs (cofsee, toe, co008, cole-type drinks)
[] 10
[] Leses than 3 par dey
[] 3-6 por day
[3 Horo than 6 per day

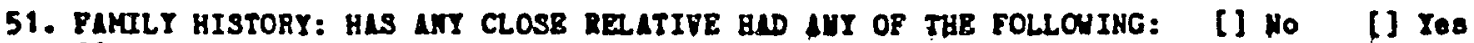

[1 Inforation not avallable

If yes, please lndloste which problen, and the persons relatfonehlp:

(1) Pald, nuabnese or paralyase of reoe

[] Epilopay or selzures

[1 Mgraine headaches.

[] D1ezlaess or vertigo

(] Monlere's disense

for off10e use oniy 